\title{
Optimal Location of Multiple Tuned Mass Dampers in Regular and Irregular Tall Steel Buildings Plan
}

\author{
Mohsen Khazaei (D), Reza Vahdani, and Ali Kheyroddin \\ Department of Civil Engineering, Semnan University, Semnan, Iran \\ Correspondence should be addressed to Mohsen Khazaei; m.khazaei@qiet.ac.ir
}

Received 28 January 2020; Revised 26 June 2020; Accepted 13 July 2020; Published 16 September 2020

Academic Editor: Edén Bojórquez

Copyright () 2020 Mohsen Khazaei et al. This is an open access article distributed under the Creative Commons Attribution License, which permits unrestricted use, distribution, and reproduction in any medium, provided the original work is properly cited.

\begin{abstract}
Tuned mass dampers are one of the most common devices for the passive control of structures subjected to earthquakes. The structure of these dampers consists of three main parameters: mass, damping, and stiffness. Tuned mass dampers reduce the amplitude of the responses affecting on a mode. In most cases, only a single TMD (tuned mass damper) or a few dampers at several points above the building height are installed on the roof of the building, requiring considerable mass and space in some parts of the structure as overhead. It is also more important to predict the elements that will meet the required mass. In this research, the performance of multiple tuned mass dampers (MTMDs) is investigated in L- and U-shaped regular and irregular tall steel buildings with 10 and 20 floors, under the near- and far-field records. Nonlinear time history analysis is also applied to evaluate the multiple tuned mass dampers effects on the seismic responses of the structures. The SAP2000 API and MATLAB genetic algorithm are used to determine the optimal location of the MTMDs in the roof plans of the buildings. The results show the effects of multiple tuned mass dampers in reducing the seismic response of acceleration, displacement, and base shear up to 50, 40, and $40 \%$ in average, respectively. The results of determining the optimum location of MTMDs in the models indicate the importance of the symmetry of the dampers relative to the centre of mass of the building.
\end{abstract}

\section{Introduction}

During an earthquake event, a significant amount of energy is applied to the structure. If this energy is not absorbed or dissipated, it causes destruction that will result in significant financial and life damage. In conventional methods, the building exhibits resistance by combining stiffness, ductility, and energy dissipation as well as inertia against dynamic forces (e.g., wind, earthquake, vibration of machines, sea waves, etc.). The damping value in these structures is very low and therefore the damped energy is negligible in the elastic behavior range of the structure. These structures experience a great deal of displacement under the influence of strong dynamic forces such as earthquakes crossing the elastic range. Inelastic displacements cause the plastic joints to be positioned locally in some parts of the structure, which in turn increases the ductility, and consequently a large amount of earthquake energy is dissipated by local degradation in the lateral resisting system. In recent years, many efforts have been made to apply modern control devices to the structures exposed to earthquakes. These devices prevent the degradation of the structural elements during earthquake by absorbing some of the energy input into the structures [1]. Different vibration control methods include passive, semi-active, active, and hybrid, and various factors such as efficiency, weight, device and implementation cost, maintenance, and safety influence the choice of a specific type of vibration control device.

Tuned mass dampers (TMDs) are a type of passive damping systems that attaches to the main structure as a secondary mass and reduces the dynamic response of the structure through damping and stiffness, which is widely used in control engineering systems and other civil engineering structures $[2,3]$. The mass dampers have a mass of about 1 to $5 \%$ of the total mass of the structure, which is connected by a spring and dampers to the location of the 
structure which usually has the most displacement. Mass dampers are usually tuned by the frequency of the main mode of the structure. When this mode is stimulated, the mass damper absorbs and dissipates the energy of the earthquake by anti-phase movement toward structure. Ease of installation and implementation is one of its benefits. Multiple tuned mass dampers (MTMDs) consist of several single mass dampers that can be designed and installed in parallel or series in structures. They can be used in centralized or distributed structures. This research includes the related literature review to the topic, the governing equations of multiple distributed mass dampers, introduction of structural models used in the research, introduction of records used in analysis, model and software verification, the result evaluation of the 10 - and 20-story buildings with MTMDs in ninth and tenth stories, and the optimal location of the mass dampers in the model plans using genetic algorithm (GA).

\section{Literature Review}

In a TMD system, a specific mass is mounted at a specified location of the structure and the vibration amplitude of the structure in the first mode is controlled by a spring and a damper with specified damping and stiffness coefficients. However, when external stimulation is such that the higher modes' contribution in the response of the structure is greater than the first mode, the TMD system may have the opposite effect and increase the amplitude of vibrations. The basic idea of TMD was first proposed by Frahm [4] in 1909 and then studied by Ormondroyd and Den Hartog [5] in 1956. For seismic applications, some researchers like Chen and Clark [6, 7] have shown that the individual TMD system is not effective in reducing seismic responses. There are two reasons for this: first, earthquake loads are a kind of shock and quickly reach maximum values. Secondly, earthquake shocks comprise a wide range of frequency components and often contain distinct vibrations in both the basic mode and the higher modes of tall building structures. The single-mass dampers are tuned for basic frequencies and are not capable of controlling higher vibrational modes. Reports have suggested that single mass dampers can enhance higher modal responses due to the coupling between basic and higher modes. Due to the disadvantages of using single mass dampers, many researchers have proposed the MTMDs system, multiple tuned mass dampers, which tune and direct different modes and are located in the different locations of the structures. McNamara [8] in 1977 investigated the effect of TMD vibration filtration under white noise and the application of this method under vibration induced by wind in building. Work on TMD was extended by Warburton and Ayorinde [9] in 1980 to determine the optimum values of TMD parameters attached to elastic structures, rectangular plates, and cylindrical shells subjected to periodic loads. Warburton calculated the optimal damper properties for a series of stimuli and response parameters. In 1994, Villaverde and Koyama [10] tested three different structures equipped with TMD, including a 2-dimensional 10-story shear frame, a 3-story frame, and a three-dimensional bridge under 9 different earthquake types. Wirsching and Campbell [11] in 1974 solved the problem of optimizing the TMD parameters and the natural frequency and damping ratio attached to the multi-story structure and analyzed the response of the first main mode of the main structure equipped with a TMD under the Earth lateral vibration of Gaussian white noise. Abé and Igusa [12] and Jangid [13] investigated the effect of multiple tuned mass dampers according to the structural model of Figure 1 on the main structure. Using asymptotic analysis for the apparent resistance of attached devices, they concluded that several dampers with natural frequencies close to each other which cover a wide frequency range can be represented by an equivalent damping proportional to the dampers' mass.

Li [14] in 2002 investigated the impact of the broadband vibrations of the Earth on different types of linear MTMDs designs and utilized dynamic displacement magnification factor as well as dynamic acceleration magnification factor as the optimal design criterion and then they were compared with 5 MTMDs models with different combinations of stiffness, mass, damping coefficient, and damping ratio. In 1995, Kareem and Kline [15] investigated the method of control using MTMDs attached to a real-scale vibrating structure. They validated previous results and studies and showed that the efficiency of MTMDs in the natural frequency range is more dependent on the number of mass dampers than the damping ratio parameter. Abdullah et al. [16] investigated the adjacent structures using STMD or shared tuned mass damper system to reduce the vibration of structures and the effects of pounding. Due to the connection of STMD to both structures, the problem of tuning the stiffness and damping will be solved. Their results show that the STMD system performs better than TMD and is an effective way to reduce the impact of pounding on adjacent buildings and vibrations. Zahrai and Ghannadi [17] investigated the effect of tuned mass dampers on the control of earthquake-prone buildings by studying the effect of TMD vibration control on 5-, 8-, 10-, and 15-story special bending frame buildings in both directions. Tuan and Shang [18] investigated the effects of TMD on the dynamic response of the Taipei 101 tower, explaining that the tower is subjected to wind load and earthquake excitation. The simulated results were compared with the wind tunnel test and the desired records. The results showed the damper effect in reducing the vibration of the wind, although it did not have much effect in reducing the vibration of the earthquake force. Hirde and Aher [19] investigated the seismic response of a concrete building with irregular plan under earthquake force with pushover analysis. Models were analyzed with irregular and L-shaped plan and compared with irregular plan with 5, 10, and 15 floors. Soto and Adeli [20] used eight different sets of equations to tune the parameters of a mass damper attached to a 5-story building with irregular plan and height and exposed a 15-story and 20-story building with irregular planes to earthquake loading. Also, bi-directional mass dampers with pendulum mass dampers with 3 different plan and height irregularities from 5 to 20 stories and period from 0.55 to 4.25 seconds were exposed to Loma Prieta earthquake and their performances were compared. They also 


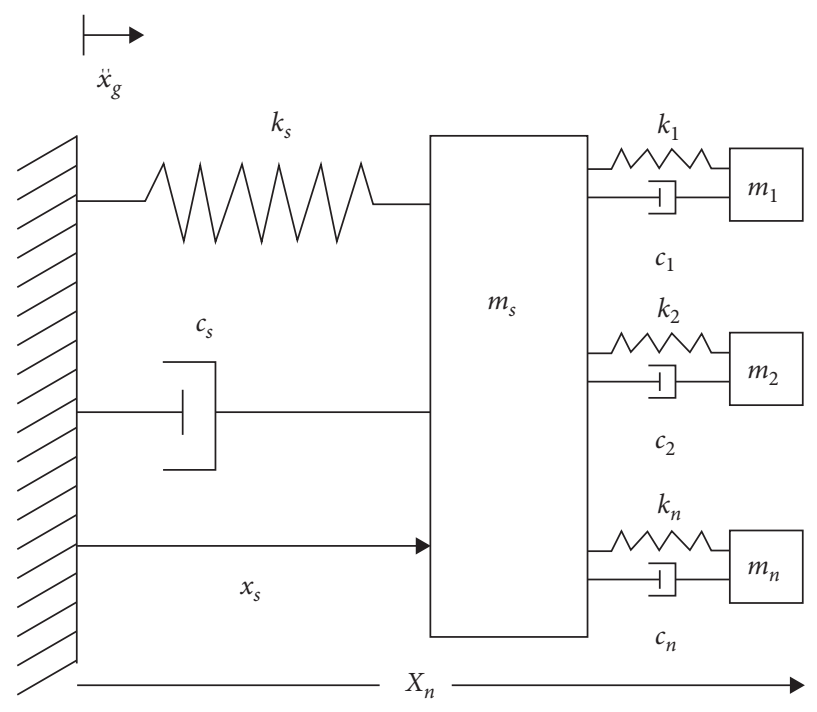

FIgURE 1: Structural model of MTMDs [13].

investigated the vibration control of irregular high-rise buildings using mass dampers and bi-directional mass dampers. Wakchaure et al. [21] examined various irregularities with analytical methods during earthquakes. Valmundson and Nau [22] investigated the range of mass, strength, and stiffness for regular buildings by UBC regulations. Selected structures are two-dimensional with 5, 10, and 20 floors, and irregularity is created by changes in the properties of the floors. Reddy et al. [23] concluded that mass dampers with mass percentages of 5 are more effective and the dimensions of the dampers should be proportional to the frequency of the structure. Bagheri and RahmaniDabbagh [24] used a viscous damper with mass damper to control the vibration of structures and concluded that the mass dampers significantly reduced the structural response and suggested an optimum mass damper (combined mass and viscose dampers) without the need for viscous damper with appropriate performance to be used. Wang et al. [25] applied mass dampers to control the bridge deck eddy vibrations and found that the mass dampers perform well in reducing bridge deck oscillation response. Li and Peng [26] proposed a new frequency-hopping-based design method for nonlinear mass damper, based on which the mass damper performs better than the linear design method. Lu et al. [27] investigated 5- and 20-story models as nonlinear benchmark structures for comparing optimum mass dampers and particle dampers. Their results showed that particle dampers offer better control effects than mass dampers in the responses such as maximum rotation of the plastic joints, energy absorption, and relative displacement between the main structure and the dampers. Lin [28] invented a type of mass dampers called TSMD that is formulated using three-degree-of-freedom modal properties of triple vibrational modes in a building with a two-way asymmetric plan whose performance has been validated by the frequency response function and seismic responses of a single-story and 20-storey structure with asymmetric plan. Lu et al. [29] pointed out that in recent years a great deal of attention has been paid to the particle damper, which is very similar to mass dampers, although they have different damping mechanism. The results showed that vibration control with particle dampers has partially better performance than mass dampers on linear and nonlinear indices such as maximum rotation of plastic joints, energy absorption, and similar items. Kamgar et al. [30] investigated the optimum design of mass dampers considering the effects of soil-structure interaction and high-rise structures. For this purpose, a 40-story shear frame was selected and WOA (Whale Optimization Algorithm) algorithm was applied to optimize TMD parameters. Their results indicate that the soil type and selected function influence the optimal design of the mass damper system. Elias et al. [31] compared the performance of a distributed multiple mass vibration absorber on a nonlinear structure with a single vibration absorber. The results showed that the mass damper distribution would have favorable effects on structures exposed to earthquake excitation. Rahmani and Könke [32] investigated the optimal location and parameters of mass dampers in high-rise buildings using genetic algorithms. They used multiple mass dampers distributed at building height and found that, at higher modes, distributed dampers at building height are more effective than mass dampers, and the optimal position of the dampers is highly dependent on the frequency of earthquake excitation. Yucel et al. [33] developed an ANN (artificial neural network) model to estimate the TMD parameters and the long numerical repetition process used in optimization. The aim of the research is to develop a method for mechanical systems including structures exposed to seismic loads. Keshtegar and Etedali [34] suggested a method based on the dynamic parameters of the structure for the optimal design of mass dampers, which output more accurately than other algorithms. Nigdeli and Bekdaş [35] in their research examined several dampers on the structural floors. They concluded that the application of the damper at several points in the structure has a more favorable effect than the placement of a damper on the roof of a building. Shahi et al. [36] examined the effects of soil/ structure interaction on the seismic behavior of structures and their performance. Etedali et al. [37] investigated the performance of TMD and FTMD in seismic control of tall buildings under near-field earthquakes, including soil and structural interactions. In their study, they used a 40-story structure and concluded that the FTMD performed better than the TMD in terms of story placement, drift, and acceleration parameters. Now, considering the research history of researchers on mass dampers and their focus on the use of single dampers on the roof or the distribution of dampers on building floors, this study investigates the optimum location of multiple distributed dampers in the roof plan especially in buildings with plan irregularities, and changes in seismic parameters have been investigated by changing the damper position in the roof plan.

\section{Governing Equations of TMD}

To determine the MTMDs parameters, Sadek et al.'s [38] (according to equations (1)-(4)) method which is provided 
for multi-degree-of-freedom structures is utilized as an initial value and sample:

$$
\begin{aligned}
& f=\frac{1}{1+\mu \varnothing}\left[1-\beta \sqrt{\frac{\mu \varnothing}{1+\mu \varnothing}}\right] \\
& \xi=\phi\left[\frac{\beta}{1+\mu}+\sqrt{\frac{\mu}{1+\mu}}\right], \\
& M_{n}=\frac{\left(\sum_{1}^{n} m_{i} \phi_{i, n}\right)^{2}}{\sum_{1}^{n} m_{i} \phi_{i, n}^{2}} \\
& m_{\mathrm{TMD}}=\mu \cdot M_{n}, \\
& K_{\mathrm{TMD}}=\omega_{0}^{2} f^{2} m_{\mathrm{TMD}} \\
& C_{\mathrm{TMD}}=2 \xi \omega_{0} f m_{\mathrm{TMD}}
\end{aligned}
$$

where $f$ is optimal frequency, which is the ratio of the damper frequency to the structure frequency, $\xi$ is the optimum damping ratio, $\mu$ is the mass ratio which is the ratio of damper mass to the structural mass, $\beta$ is the damping ratio of the structure, $\phi$ is the mode shape at the location of the TMD such that the coefficient of the modal contribution is equal to the unit, $M_{n}$ is the effective mass of the first mode or any mode that the damper is set to control, and $m_{\mathrm{TMD}}, K_{\mathrm{TMD}}, C_{\mathrm{TMD}}$ are the mass, stiffness, and the damping of the TMD, respectively.

\section{Structural Models}

4.1. Assumptions and Loading. The mechanical properties of ST37 steel are as follows (Table 1).

All the structures have been modelled as 3D models and analyzed with nonlinear dynamic analysis. The sample structures are considered to be steel structures with special ductility. The dead and live loads of the floors are $500 \mathrm{kgf} /$ $\mathrm{m}^{2}$ and $200 \mathrm{kgf} / \mathrm{m}^{2}$, respectively, floors' height is $3.2 \mathrm{me}$ ters, and the structure is made from 5 bays with 6-meter length and regular plan. According to Soto and Adeli [20] researches referred to in the literature review, the mass ratio of 3 percent for the design of dampers and the damping ratio of $2 \%$ for structures are considered based on ASCE2010. The region with very high risk and the soil of Type III are assumed for building design. The elements' mass is ignored and the rigid diaphragm is applied to floors. The axial length change of beam elements is also ignored. The rigid-zone factor is assumed to be 0.5 . The effective variables in seismic coefficient (e.g., $\mathrm{C}=\mathrm{ABI} / R_{\mathrm{u}}$ ) are considered as in Table 2. The effective mass of the structures is comprised of the dead load plus $20 \%$ of the live load.

4.2. Structural Element Design. After spectral analysis, the structural elements are designed in SAP2000.v.19.2 software. AISC360-10 regulation is used to design members and seismic criteria are applied to design members. The utilized sections are HEB for beams and BOX for columns.

\section{Seismic Records Selection}

To determine the impact of the control system, 7 records from 7 different near-field earthquakes and 7 far-field earthquakes have been selected. In order to investigate the effects of damper in different models, earthquake records have been applied in one direction to the structure of analytical models. The properties of the selected records are given in Tables 3 and 4. Different seismic records with different PGA and fault distance are selected to consider the impacts of different frequency contents of earthquakes.

5.1. Seismic Records Normalization. According to Code 2800, the accelerometer data used for structural analysis must be normalized. To normalize them, after scaling them to their maximum value (PGA), the accelerometer data response spectrum is provided for a $5 \%$ damping. Then, the obtained spectra of the accelerometer data are averaged and compared over the time intervals of $0.2 \mathrm{~T}$ and $1.5 \mathrm{~T}$, so that according to the 2800 code the average spectrum should be 1.4 times larger than the standard code 2800 spectrum [39]. After the response spectrum of the earthquake records is obtained, their averages are compared with the 2800 standard spectrum and scaled as follows (Figure 2).

\section{Multiple Tuned Mass Damper (MTMD) Properties}

In this paper, according to Soto and Adeli [20] research, which is based on thorough investigation of various researcher expressions and design parameters of mass dampers, the optimum mass ratio of the damper is selected to be $3 \%$. The mass damper frequency of the main structure is also considered to be 1.25. Due to the study of the application of dampers and their torsional effects on structural models, the mass of dampers has been applied to the models in two directions. The parameters related to the mass damper are calculated and presented for the regular and irregular 10-story model in Table 5.

\section{Geometry and Placement of Dampers}

The plan used in the models is a regular and irregular square with 5 bays with 5-meter openings for regular models. Irregular plans according to the definition of geometrical irregularities mentioned in the irregular plans based on the definition of plan geometrical irregularity in 4 th edition 2800 code [39] have been developed and defined for analysis in SAP2000 software. The utilized mass dampers in the models are defined as in Figure 3.

In this research, dampers are used in three conditions: at first, at one point on the roof, second, at two points on the roof, and third, at four points on the roof. The placement of the dampers is given in Figures 4-6.

\section{Verification}

In this study, for the purpose of verification, the effects of multiple mass dampers on the seismic behavior of 3-story 
TABle 1: Mechanical properties of steel.

\begin{tabular}{lcccc}
\hline Expected ultimate $\left(F_{\mathrm{ue}}\right)$ stress & Expected yield $\left(F_{\mathrm{ye}}\right)$ stress & Poisson coefficient $(v)$ & Ultimate $\left(F_{\mathrm{u}}\right)$ stress & Yield stress $\left(F_{\mathrm{y}}\right)$ \\
\hline $4070 \mathrm{~kg} / \mathrm{cm}^{2}$ & $2640 \mathrm{~kg} / \mathrm{cm}^{2}$ & 0.3 & $3700 \mathrm{~kg} / \mathrm{cm}^{2}$ & $2400 \mathrm{~kg} / \mathrm{cm}^{2}$ \\
\hline
\end{tabular}

TABle 2: Seismic parameters of models.

\begin{tabular}{lccccccc}
\hline Models & $R_{\mathrm{u}}$ & $\mathrm{T}$ & $\mathrm{T}$. & $T_{\mathrm{s}}$ & $\mathrm{K}$ & $\mathrm{B}$ & $\mathrm{C}$ \\
\hline Regular 10-story & 7.5 & 1.07 & 0.15 & 0.7 & 1.42 & 1.632 & 0.076 \\
Regular 20-story & 7.5 & 2.26 & 0.15 & 0.7 & 1.88 & 1.134 & 0.053 \\
\hline
\end{tabular}

structure have been investigated experimentally by Chen and $\mathrm{Wu}$ [40]. The studied structure in Chen et al.'s research with a $1 / 4$ scale steel bending frame was examined at the seismic table of Rolla University. Structural dimensions are 48 inches long, 24 inches wide, and 100 inches high, and the structures are shown in Figure 7. OPENSEES software has been used to validate the experimental studies of multiple mass dampers in the paper. The reason for using is efficiency, fast analysis and processing, high accuracy, and open source nature of this software.

This structure is designed to test the control of a structure with a hydraulic actuator placed on the first roof. The model is restrained with steel braces in three floors and stimulated with a hydraulic Jack. Structural restraint with steel braces has no role in the structural behavior and is solely applied to evaluate the performance of the mass dampers. Each mass damper consists of a mass block, a set of continuous springs, and a sliding shaft ball bearing. The mass block attaches to the base wall of the damper via extension springs and can only move along the dual shafts. The natural frequency of the damper can be adjusted using different types of springs. Since no damping element has been added to the damper system intentionally, friction between the bearings and the shafts forms the main damping part of the system [40].

8.1. Model Structural Properties. The concentrated masses on the first, second, and roof are 445, 394, and $388 \mathrm{~kg}$, respectively. Forced excitation experiments were performed to identify the structural parameters for all three modes. First, several sine sweep experiments were performed to identify approximately the natural frequencies of the structure. Then, a series of concurrent tests with different excitation frequencies were performed around the natural frequencies of the tested structure. The modal properties of the test are shown in Table 6.

8.2. Dampers Properties. Six different types of continuous springs were used consistently throughout the shake table tests. Three specimens were selected randomly and with determination of resilience constant. The properties of the dampers are given in Table 7.

The damper free vibration pattern for the first mode is shown in Figure 8.

8.3. Verification Results. The following results are obtained and compared with the values of the paper by studying the floor accelerations in the dampers with masses of 60 and
$80 \mathrm{~kg}$. It should be noted that this issue has been analyzed simultaneously in the OPENSEES and MATLAB programs. The comparison diagram of the controlled structure acceleration results with damper in software with the experimental model results is shown in Figure 9, which is confirmed by a slight difference. The response of the normalized accelerations ( $\ell^{2}$ norm) of the structure controlled by the mass dampers on the roof floor is presented in Figure 9. It can be seen in the figure that multiple mass dampers can reduce the normalized acceleration response of the stories by more than $20 \%$.

\section{Nonlinear Time History Analysis Results of the Regular 10-Story Model}

Mass dampers reduce the applied force to the structures by structural mass increase approach and the change in the stiffness and mass matrices of the structures, which results in a change in the effective time period of the structure and getting the structure away from the acceleration sensitive boundary. When the dampers are in a position of the structures, the control of seismic response of the structures is not significant and has little effect on the response of the structures with higher predominant modes. Thus, when the damper is located at more than one point, it is possible to control the seismic response of the structures by controlling the impact of higher modes.

9.1. Roof Displacement Results with Dampers in the Tenth Story. To evaluate the effect of tuned mass dampers on the seismic response of regular and irregular structures in different damper position conditions, the maximum lateral displacement of the roof is extracted for near- and far-field records. In this study, dampers are mounted on the roof floor in three conditions: one, two, and four dampers. The records used in this study are 7 near-field and 7 far-field records. In this section, the displacement value for each record with damper and without damper conditions is plotted. Figure 10 shows the maximum roof displacement in the ten-story model.

According to the results of the maximum displacement investigated for the 10-story structure without mass dampers and with different conditions with different mass dampers, it can be seen that utilizing tuned mass dampers in near-field and far-field records significantly reduces the displacement of the 10-story structure. It is observed that the change in the number of dampers leads to a change in the responses. The highest displacement reduction for near-field records in the case of using a damper is $43 \%$. This amount of reduced displacement is investigated toward the case of without damper. The highest amount of displacement reduction for the cases of two and four dampers is $49 \%$ and $52 \%$, respectively. The results of the far-field records also show that, 
TABLE 3: Near-field earthquake properties.

\begin{tabular}{lccccccccc}
\hline & Record & Station & Year & Dis $(\mathrm{km})$ & Mag & PGA & PGV $(\mathrm{cm} / \mathrm{s})$ & $T_{\mathrm{s}}(\mathrm{sec})$ & Duration $(\mathrm{sec})$ \\
\hline 1 & Alaska-Denali & Pump & 2002 & 2.74 & 7.9 & 0.32 & 1689 & 3.48 & 86 \\
2 & Bam & Bam & 2003 & 1.7 & 6.6 & 0.59 & 417 & 0.78 & 37.36 \\
3 & Chi-Chi & Thy101 & 1999 & 9.94 & 7.62 & 0.44 & 261.38 & 0.9 & 26.48 \\
4 & Chi-Chi & Tcu 68 & 1999 & 0.32 & 7.62 & 0.56 & 312 & 0.42 & 12.48 \\
5 & Imperial-Valley & El Centro Array & 1979 & 1.35 & 6.53 & 0.43 & 250.12 & 0.24 & 8.49 \\
6 & Kobe & Takatori & 1995 & 1.47 & 6.9 & 0.61 & 206 & 1.22 & 11.34 \\
7 & Borujerd & Silakhor & 1909 & 12 & 7.3 & 0.44 & 321 & 1.52 & 56.34 \\
\hline
\end{tabular}

TABLE 4: Far-field earthquake properties.

\begin{tabular}{lccccccccc}
\hline & Record & Station & Year & Dis $(\mathrm{km})$ & Mag & PGA & PGV $(\mathrm{cm} / \mathrm{s})$ & $T_{\mathrm{s}}(\mathrm{sec})$ & Duration $(\mathrm{sec})$ \\
\hline 1 & Chi- Chi & Chy 065 & 1999 & 83 & 7.62 & 0.6 & 130.79 & 0.62 & 28.515 \\
2 & Chi-Chi & Tap95 & 1999 & 109 & 7.62 & 0.15 & 178.062 & 0.98 & 15.8 \\
3 & Imperial-Valley & Oak-2 & 1979 & 18.87 & 5.01 & 0.24 & 148.23 & 0.32 & 12.515 \\
4 & Imperial-Valley & Outers & 1979 & 24.23 & 6.53 & 0.26 & 38.78 & 0.16 & 1.75 \\
5 & Kobe & Hik & 1995 & 95 & 6.9 & 0.14 & 110.64 & 0.6 & 17.04 \\
6 & Loma Prieta & Halls Valley & 1989 & 30.25 & 6.93 & 0.23 & 107.85 & 0.3 & 10.78 \\
7 & Manjil & Qazvin & 1990 & 49.97 & 7.37 & 0.13 & 83.79 & 0.16 & 25.71 \\
\hline
\end{tabular}

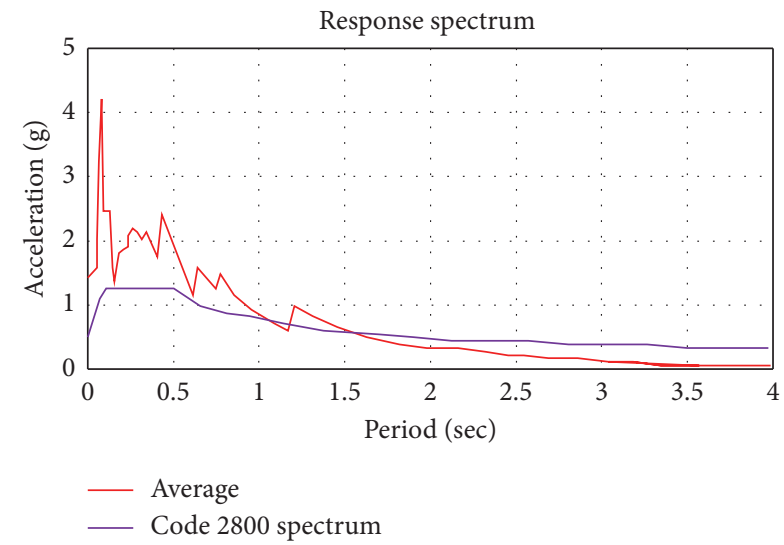

FIGURE 2: Comparison of response spectrum average of earthquake records with 2800 standard spectrum.

TABle 5: Design parameters of mass damper in regular and irregular 10-story models.

\begin{tabular}{lccccc}
\hline Model & $\mu$ & $\begin{array}{c}m_{d} \\
(\mathrm{~kg})\end{array}$ & $\begin{array}{c}k_{d} \text { (ton/ } \\
\mathrm{m})\end{array}$ & $\begin{array}{c}C_{c} \text { (ton/ } \\
\mathrm{sec})\end{array}$ & $\begin{array}{c}C_{d} \text { (ton/ } \\
\mathrm{sec})\end{array}$ \\
\hline $\begin{array}{l}\text { Regular 10- } \\
\text { story }\end{array}$ & 0.03 & 22779 & 496.65 & 212.3 & 22.07 \\
$\begin{array}{l}\text { L-shaped 10- } \\
\text { story }\end{array}$ & 0.03 & 16297 & 311.93 & 142.59 & 14.83 \\
$\begin{array}{l}\text { U-shaped 10- } \\
\text { story }\end{array}$ & 0.03 & 17531 & 227.2 & 126.22 & 13.12 \\
\hline
\end{tabular}

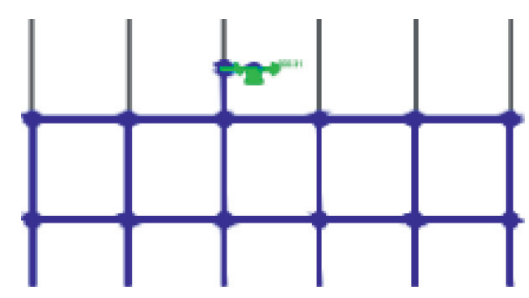

FIgUre 3: Mass application in the TMD model. in the case of one damper, the reduced mean displacement compared to the cases of without damper, two dampers, and four dampers is $45 \%, 55 \%$, and $60 \%$, respectively, but on average using four dampers reduces displacement more than using two dampers. In a number of earthquake records, especially in near-field ones, due to the frequency content and earthquake parameters, using two dampers has better results than the four dampers.

9.2. Roof Acceleration Results with Dampers in the Tenth Story. Tuned mass dampers have the greatest impact on the acceleration value of the structures and control the seismic response of the structures by getting the structures away from the acceleration sensitive region. The maximum acceleration of the roof in the ten-story model is shown in Figure 11.

Since the acceleration of the floors of a structure is influenced by the transmitted acceleration from the ground and the dynamic characteristics of the structure, therefore the mass of the structure increases with the use of mass dampers and the acceleration of the floors reduces with increasing the time period of the structure. This issue is investigated for the 10-story structure in the case of using mass dampers compared to without damper, which yields interesting results. The floor acceleration of the 10-story structure in a fixed mass is affected by the damper number and position. This issue is also investigated for near- and farfield records and the frequency content effects of near- and far-field earthquake records. It is observed that the maximum acceleration reduction for near-field records when using one, two, and four dampers is 28,46 , and $46 \%$, respectively. The results also show $36 \%, 46 \%$, and $44 \%$ reduction for far-field earthquakes, respectively. The results show the effect of the number of dampers on the acceleration reduction of the structure affected by the near- and far-field records. It is also observed that the change in the properties of the record causes a change in the seismic responses such 


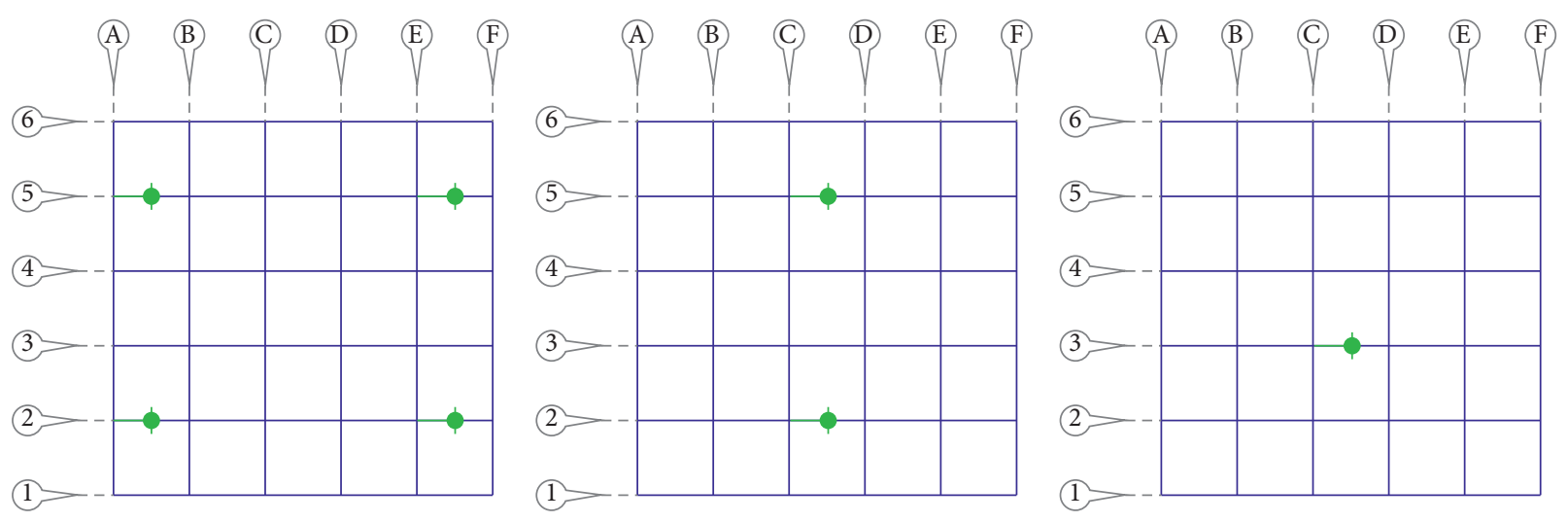

FIgURE 4: Damper at one point (right), dampers at two points (middle), and dampers at four points (left).
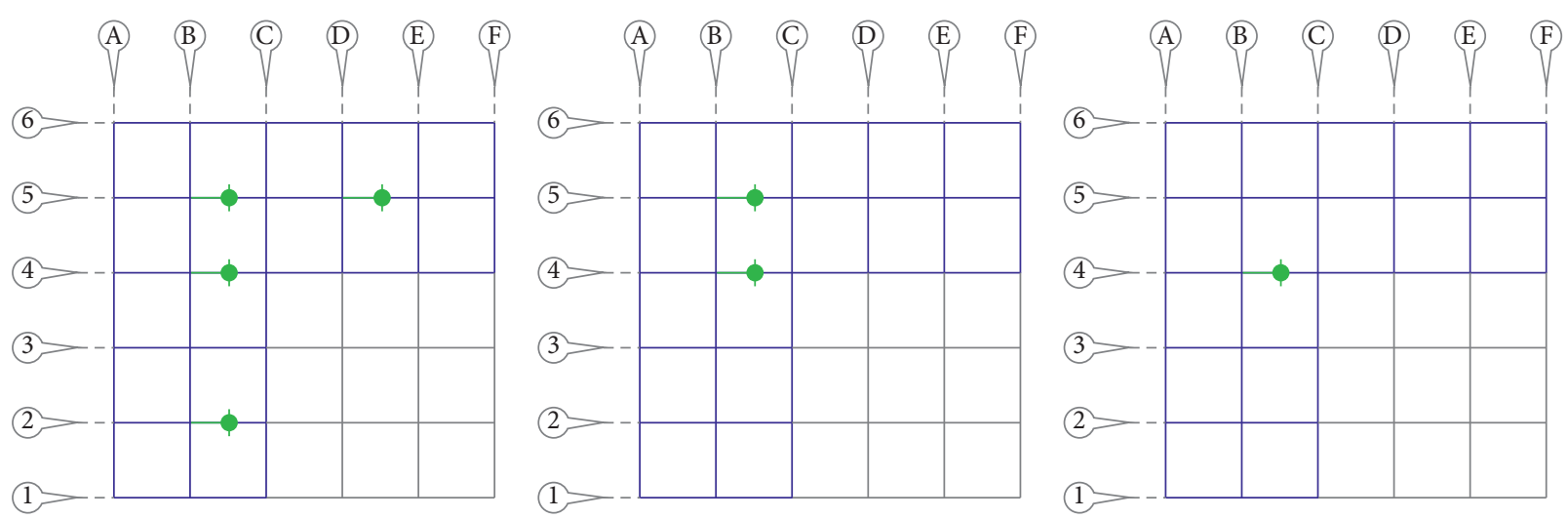

Figure 5: Damper at one point (right), dampers at two points (middle), and dampers at four points (left).
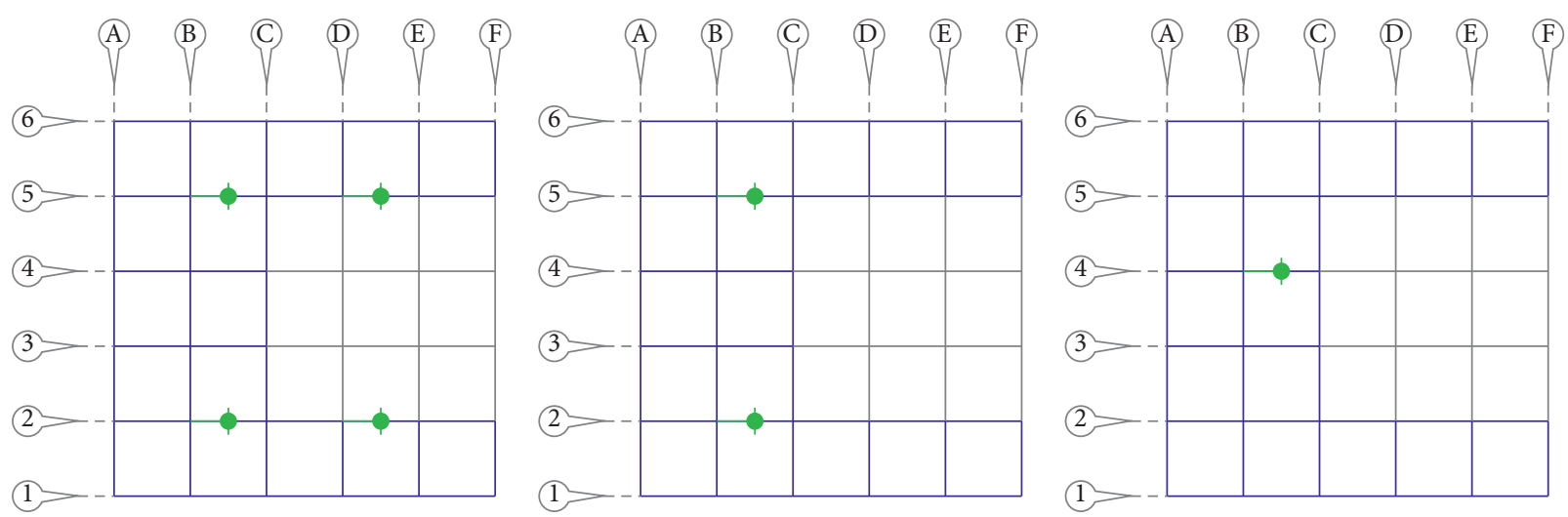

Figure 6: Damper at one point (right), dampers at two points (middle), and dampers at four points (left).

that the near-field records increase the acceleration values in the cases of using 1,2, and 4 dampers over the far-field records due to the pulse in the velocity frequency content.

9.3. Base Shear Results with Dampers in the Tenth Story. The base shear value reduces at a constant mass by changing the applied acceleration to the structure. In this section, the maximum base shear obtained from the time history analysis is presented for the near- and far-field records. The effects of the tuned mass dampers on the reflection of the earthquake force to the structures are evaluated considering the base shear, and the force dissipation is determined in different conditions considered for the multiple mass dampers. The maximum base shear in the ten-story model is given in Figure 12.

The base shear of the structures is important because any changing in the applied acceleration to the structures changes the amount of base shear. The acceleration value of the 10-story structure is investigated under the near- and far- 

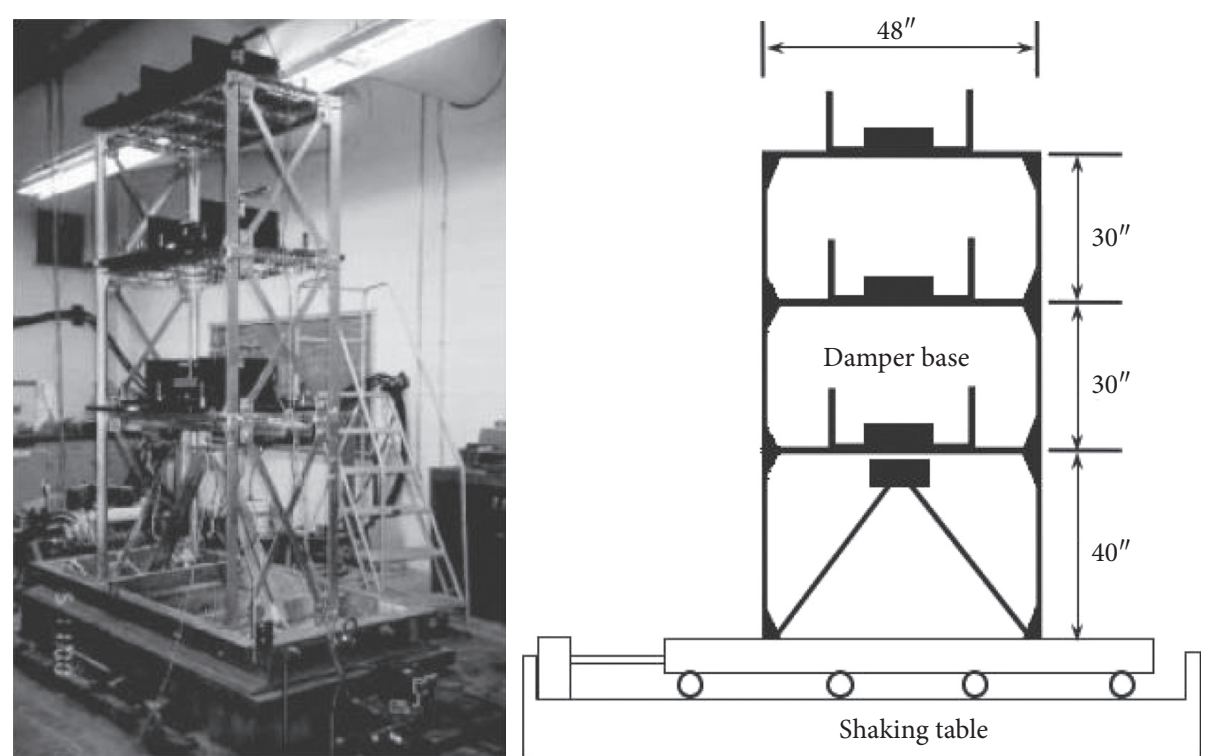

Figure 7: Studied structure on the shaking table [40].

TABLe 6: Modal properties of structure [40].

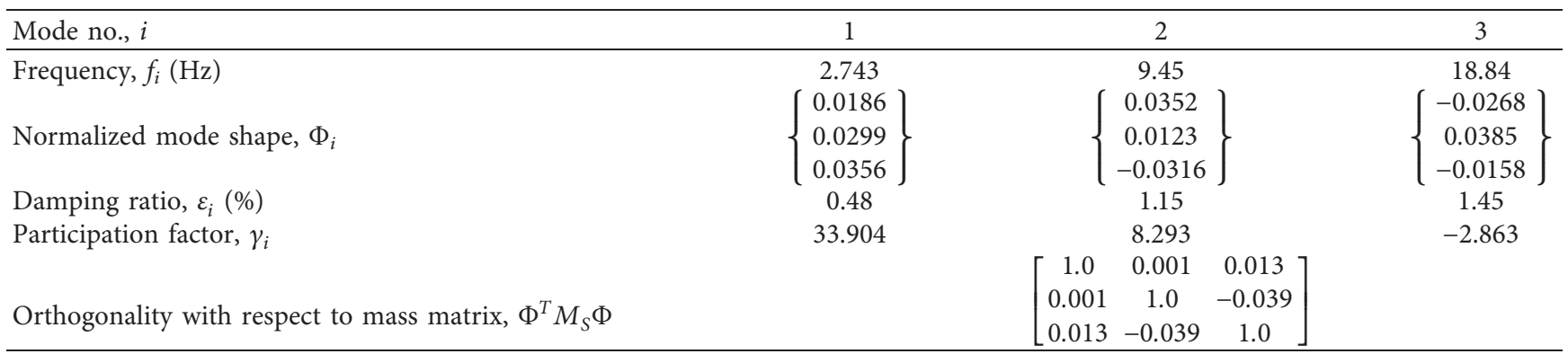

TABLE 7: Utilized damper properties in the model [40].

\begin{tabular}{|c|c|c|c|c|c|c|c|c|}
\hline \multicolumn{3}{|c|}{ Mass, $M_{s}(\mathrm{~kg})$} & \multicolumn{3}{|c|}{ Damping, $C_{s}\left(* 10^{2} \mathrm{~N} \cdot \mathrm{sec} / \mathrm{m}\right)$} & \multicolumn{3}{|c|}{ Stiffness, $K_{s}\left(* 10^{6} \mathrm{~N} / \mathrm{m}\right)$} \\
\hline$[445$ & 0 & 0 & {$[7.770$} & -4.683 & 0.257 & {$[2.669$} & -2.118 & 0.452 \\
\hline 0 & 394 & 0 & -4.683 & 8.594 & -4.224 & -2.118 & 3.397 & -1.645 \\
\hline 0 & 0 & 388 & 0.257 & -4.224 & 4.057 & 0.452 & -1.645 & 1.260 \\
\hline
\end{tabular}

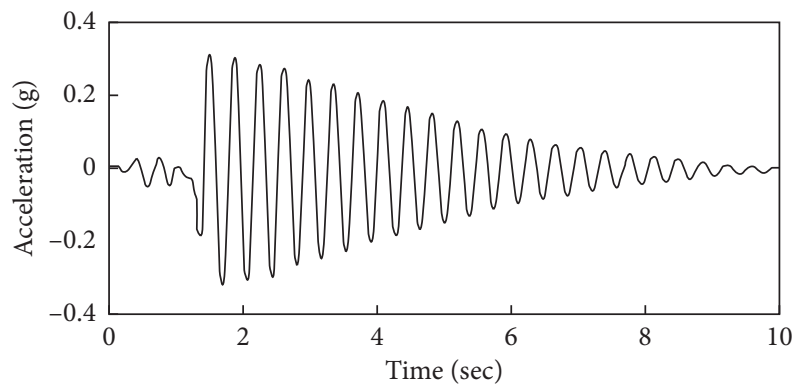

Figure 8: First mode stimulation pattern [40].

field records in the cases of with damper and without damper. The results show that, in the case of using tuned mass damper, the reduction value of applied acceleration to the structures is proportional to the reduction value of

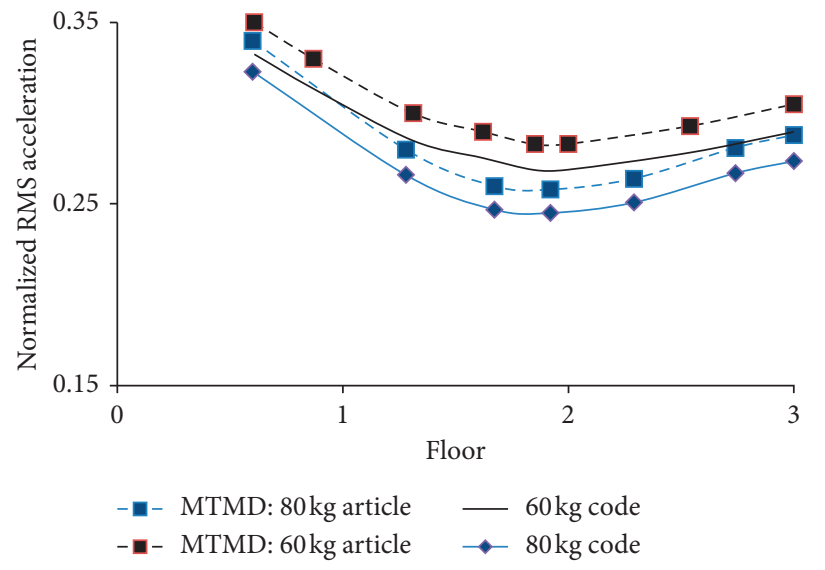

FIGURE 9: Comparison diagram of controlled structure acceleration results with damper in software analysis with obtained results of the experimental model. 


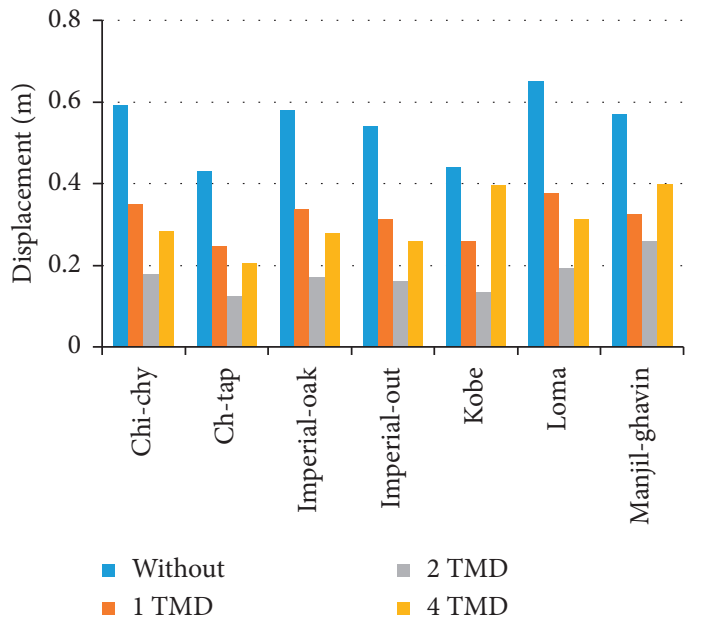

(a)

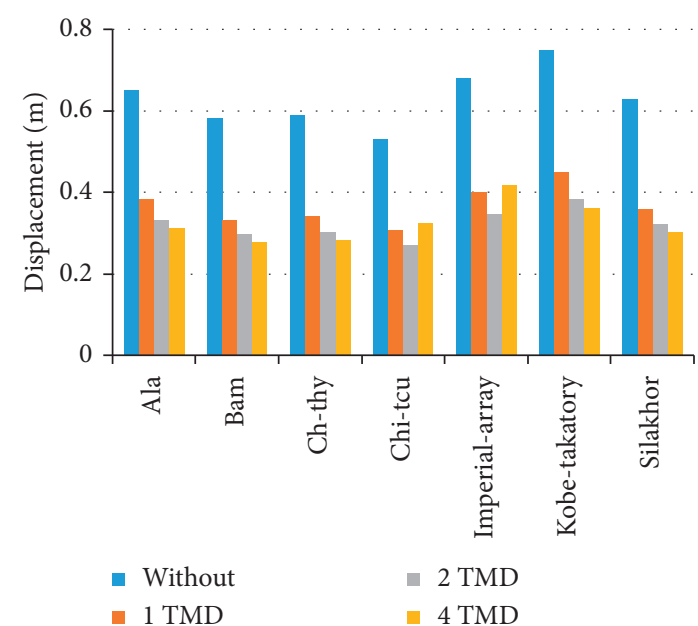

(b)

Figure 10: Maximum roof displacement under the near-field (right) and far-field (left) earthquakes in the regular 10-story model.

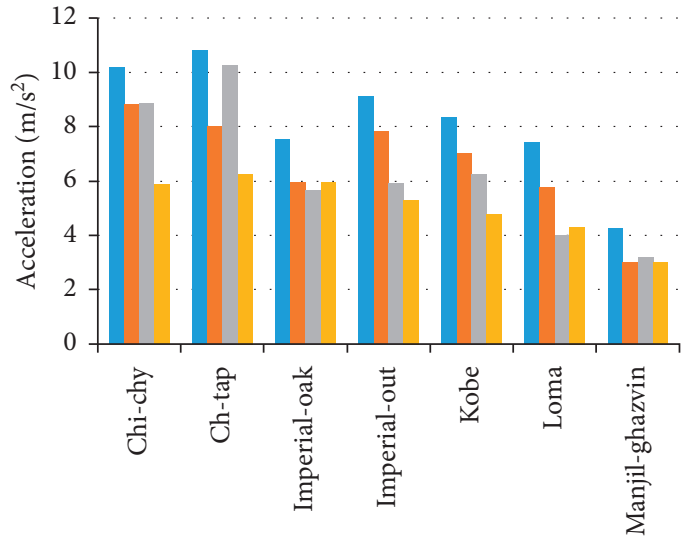

- Without

- 1 TMD

$$
\text { - } 2 \text { TMD }
$$$$
\text { - } 4 \text { TMD }
$$

(a)

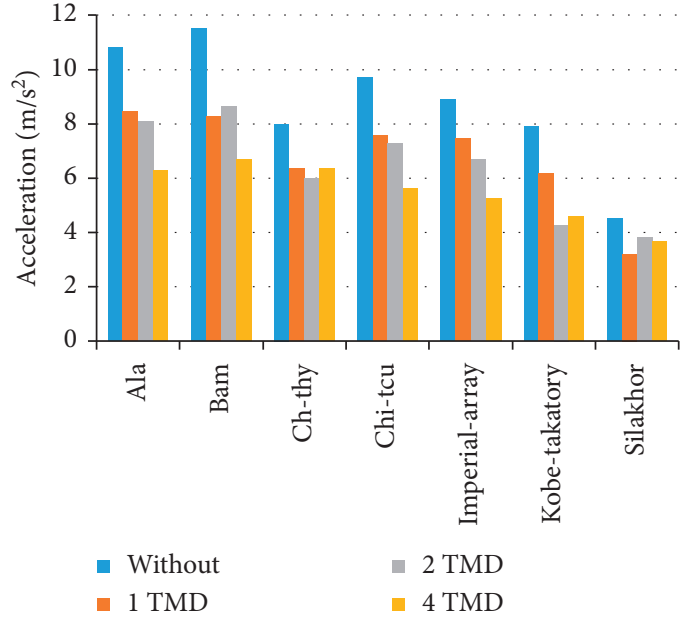

(b)

FIgURE 11: Maximum roof acceleration under the near-field (right) and far-field (left) earthquakes in the regular 10-story model.

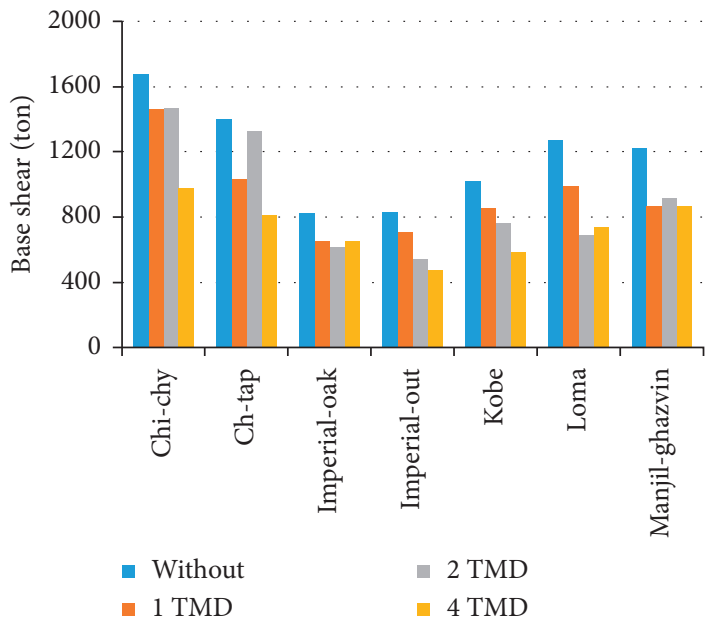

(a)

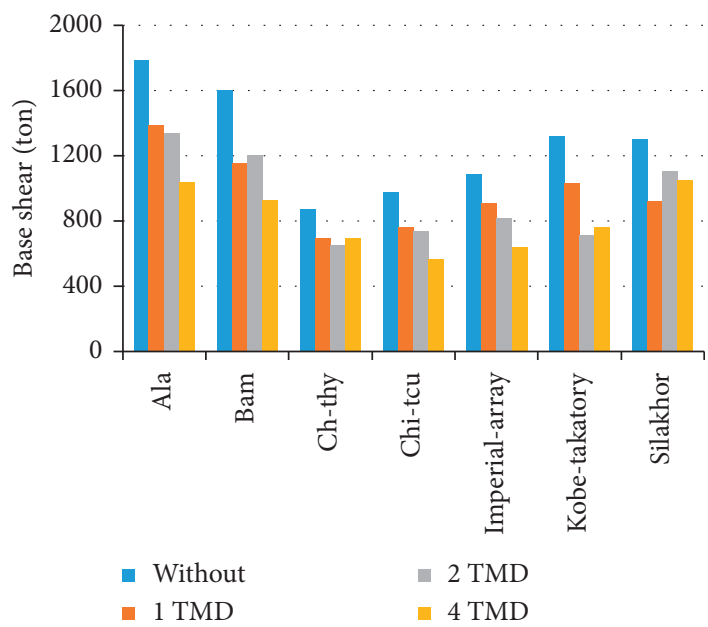

(b)

Figure 12: Base shear under the near-field (right) and far-field (left) earthquakes in the regular 10-story model. 


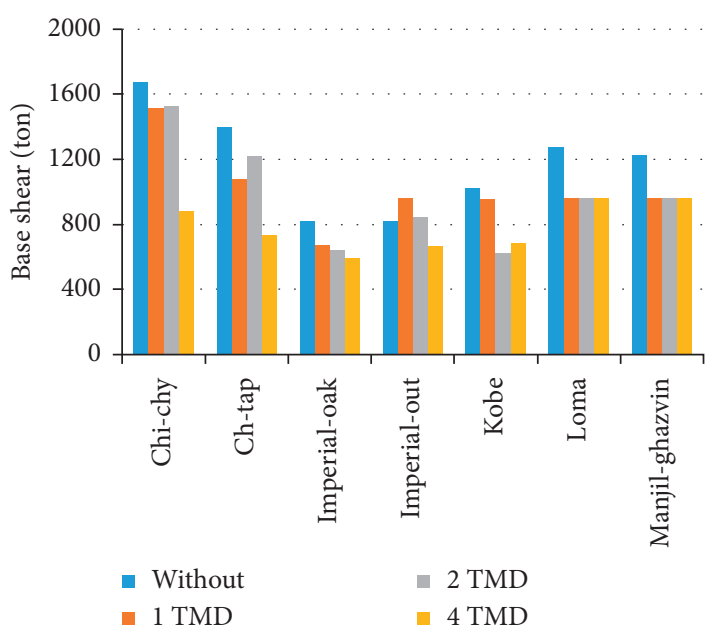

(a)

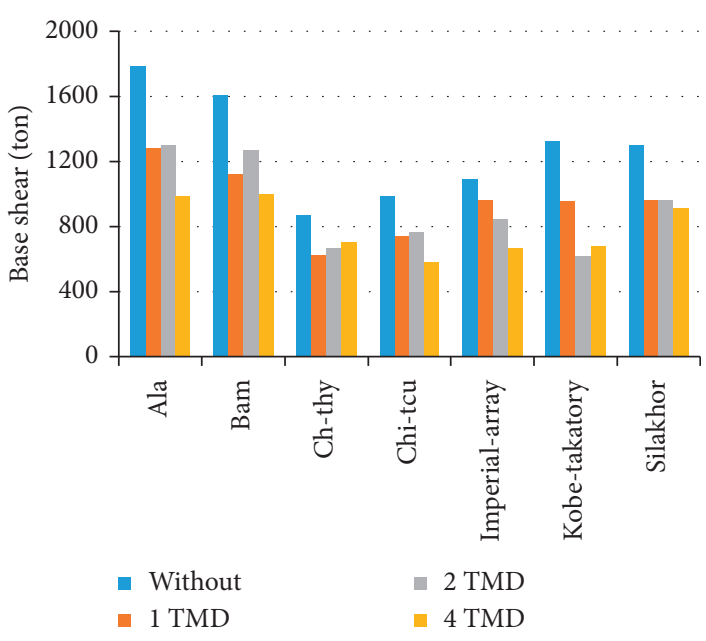

(b)

FIGURe 13: Base shear with damper in the ninth story under the near-field (right) and far-field (left) earthquakes in the regular 10-story model.

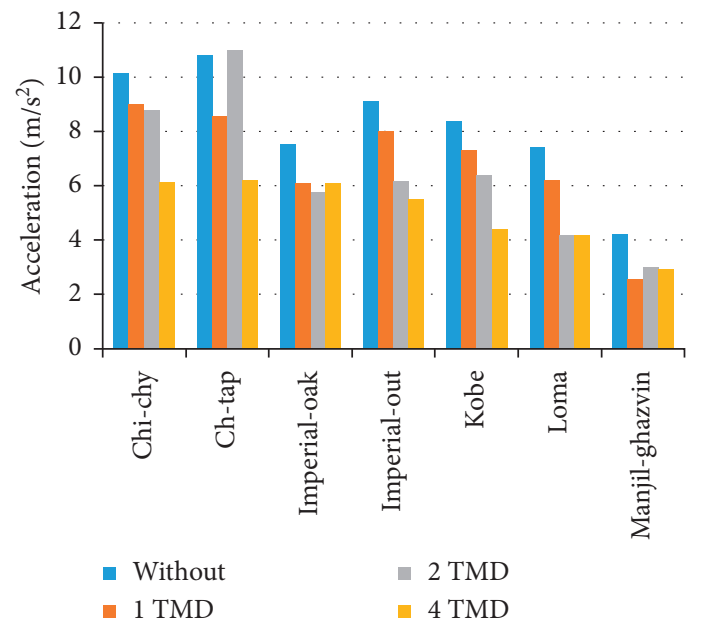

(a)

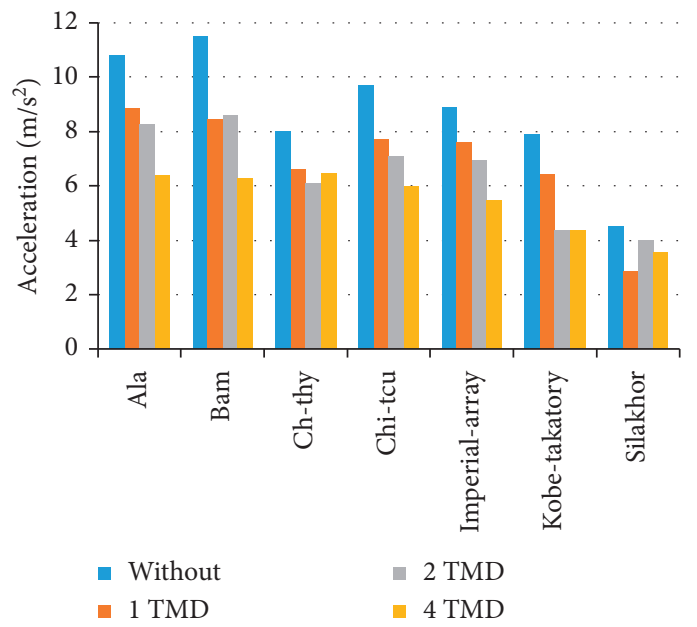

(b)

FIgURe 14: Acceleration with damper in the ninth story under the near-field (right) and far-field (left) earthquakes in the regular 10-story model.

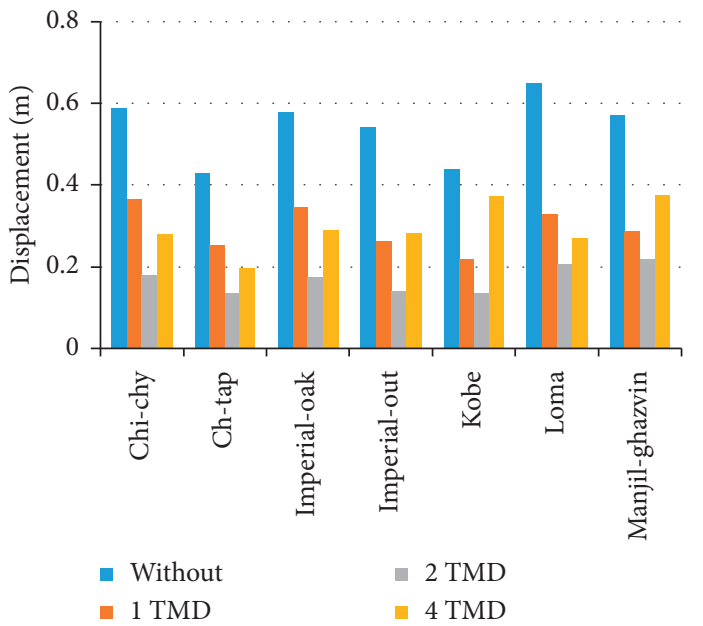

(a)

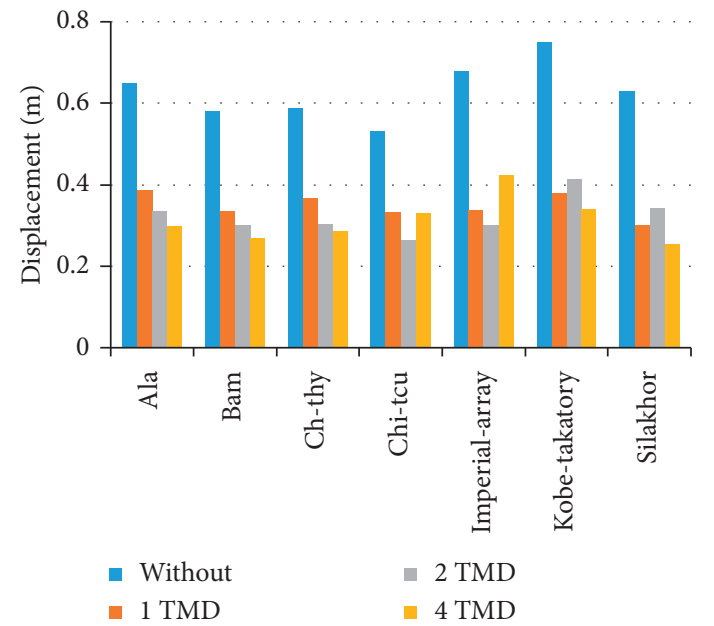

(b)

FIGURE 15: Displacement with damper in the ninth story under the near-field (right) and far-field (left) earthquakes in the regular 10-story model. 
structural base shear. This reduction is different for different dampers. In the case of using one damper, the maximum reduction for near- and far-field records is $40 \%$ and $36 \%$, respectively. The results for using two and four dampers in near- and far-field records are $46 \%, 42 \%, 46 \%$, and $44 \%$, respectively.

9.4. Base Shear Results with Dampers in the Ninth Story. In this section, the maximum base shear obtained from the time history analysis for near- and far-field records is presented. The maximum base shear in the ninth floor of the ten-story model is shown in Figure 13.

The numerical results of the seven near- and far-field records for the case that the damper is placed on the ninth floor of the 10-story structure show that using tuned mass dampers on the penultimate floor of the structure also has a significant effect on reducing the base shear value. On the other hand, it can be seen that changing the number of dampers changes the base shear value, and in some cases, having more dampers leads to noticeable reduction in base shear. The numerical analysis of base shear for near-field records shows that, in the cases of using one, two, and four dampers, the maximum reduction is 30,53 , and $48 \%$, respectively. For far-field records, these values are 24,39 , and $33 \%$, respectively.

9.5. Acceleration Results with Dampers in the Ninth Story. In this section, the maximum acceleration obtained from the time history analysis for near- and far-field records is given. The maximum acceleration in the ninth floor of the ten-story model is given in Figure 14.

Studying the maximum acceleration of the roof for the case where the dampers are placed on the ninth floor of the 10 -story structure indicates that utilizing tuned mass dampers on the penultimate floor can control the acceleration of the structure. It is observed that the change in damper position has a different effect on the acceleration values of the roof. The change in the number of dampers in the plan also causes a change in the maximum value of roof acceleration. Numerical analysis of the roof acceleration shows that the maximum acceleration reduction of the floor for the cases with one, two, and four dampers under the near-field records is 36,44 , and $45 \%$, respectively. This value for far-field records is 39,43 , and $47 \%$, respectively.

9.6. Roof Displacement Results with Dampers in the Ninth Story. In this section, the displacement obtained from the time history analysis for near- and far-field records is given. The maximum displacement in the ninth floor of the tenstory model is given in Figure 15.

By studying the maximum lateral displacement of the roof in the case the damper is located in the ninth-floor, it can be seen that the change in the number of the dampers in the ninth floor has a different effect on the lateral displacement reduction of the roof. The maximum reduction in the lateral displacement in the case of using TMDs with one, two, and four dampers for near-field records is 52,55 , and
$59 \%$, respectively, and these values for far-field records are 51,74 , and $58 \%$, respectively. The placement of the dampers in the ninth floor rather than the tenth floor affects the dynamic properties of the structure and changing the frequency characteristics of the structure including the time period of the structures alters the effects of the dampers in the seismic response of the structure. In general, regarding the location of the mass dampers in the tenth and ninth floors of the regular ten-story model, it can be concluded that using the mass dampers has significant effects on the seismic responses of the structures up to $50 \%$ reduction in average in the roof acceleration, displacement, and the base shear. Using 2 or 4 dampers compared to one damper shows a significant reduction up to $25 \%$ in the seismic response of the structure. The response reduction variations in near-field records are more noticeable than those in the far-field, due to the frequency content and the details of earthquake parameters. The responses also show better adaptation of the mass dampers to analytical models with near-field records. The placement of the dampers in the tenth floor shows little difference in the seismic response compared to the ninth floor in the present analytical model. It is worth noting that the application of dampers is also investigated in the irregular structures and the maximum percentage reduction in the regular and irregular structures is shown in Tables $8-10$.

The results of the tables show the significant impact of the mass dampers on the reduction of seismic parameters and responses. The percentage of reduction in the models with multiple mass dampers is more than single dampers. In the case of base shear response, increasing the number of dampers from one to four increases the percentage reduction in all models and the responses are mostly reduced in nearfield records and the desirable capabilities of the dampers are noticeable in controlling the displacement and accelerations of the structures in near-field records. In the case of roof displacement, as the number of dampers increases, an increase in the percentage of response reduction is observed, and the response of roof displacement is further reduced in far-field records such that, in the special cases, using two dampers under far-field earthquake shows a reduction by approximately $80 \%$. Increasing the number of dampers has also remarkable effect in the reduction of acceleration responses.

\section{Number and Location Optimization of MTMDs}

In the optimization section, the effect of 2 and 4 dampers on the last floor of the 10- and 20-story structures has been investigated. For this purpose, a genetic algorithm has been used to find the optimal position of these dampers, so that the position of the structural nodes in the roof level (with $N$ number of variables equal to the number of dampers) is considered as a variable and the optimal combination of these variables has been obtained. The algorithm cost function is formed using the SAP2000 API software. For each chromosome in the population consisting of the following variables (for example, 5, 9, 12, and 32 for the 
TABLE 8: Maximum displacement reduction percentage of roof in the regular and irregular 10-story models.

\begin{tabular}{|c|c|c|c|c|c|c|}
\hline \multirow{2}{*}{$\begin{array}{l}\text { Roof displacement reduction \% } \\
\text { Record }\end{array}$} & \multicolumn{2}{|c|}{ 1-damper } & \multicolumn{2}{|c|}{ 2-damper } & \multicolumn{2}{|c|}{ 4-damper } \\
\hline & Near-field & Far-field & Near-field & Far-field & Near-field & Far-field \\
\hline Regular 10-story & 43 & 45 & 49 & 70 & 52 & 52 \\
\hline L-shaped 10-story & 40.85 & 51.75 & 48.02 & 80.5 & 50.44 & 56.16 \\
\hline U-shaped 10-story & 49.45 & 51.75 & 56.35 & 80.5 & 50.44 & 59.8 \\
\hline
\end{tabular}

TABLe 9: Maximum acceleration reduction percentage in the regular and irregular 10-story models.

\begin{tabular}{lccccc}
\hline \multirow{2}{*}{$\begin{array}{l}\text { Roof acceleration reduction \% } \\
\text { Record }\end{array}$} & Near-field & Far-field & Near-field & Near-field & \multicolumn{2}{c}{ F-damper-field } & Near-field \\
\hline Regular 10-story & 28 & 36 & 46 & 46 & 46 \\
L-shaped 10-story & 27.72 & 32.04 & 40.02 & 45.54 & 44 \\
U-shaped 10-story & 29.96 & 38.52 & 49.22 & 49.22 & 45.54 \\
\hline
\end{tabular}

TABLE 10: Maximum base shear reduction percentage in the regular and irregular 10-story models.

\begin{tabular}{lccccc}
\hline Base shear reduction \% & \multicolumn{2}{c}{ 1-damper } & \multicolumn{2}{c}{ 2-damper } & \multicolumn{2}{c}{ 4-damper } \\
Record & Near-field & Far-field & Near-field & Far-field & Near-field \\
\hline Regular 10-story & 40 & 36 & 46 & 42 & 46 \\
L-shaped 10-story & 44.8 & 38.52 & 51.52 & 36.54 & 51.52 \\
U-shaped 10-story & 41.6 & 32.04 & 40.94 & 43.68 & 47.84 \\
\hline
\end{tabular}

TABLE 11: Genetic algorithm parameters.

\begin{tabular}{lcccc}
\hline Mutation rate (\%) & Selection rate (\%) & Generation & Population & Algorithm type \\
\hline 20 & 70 & 15 & 30 & Continuous \\
\hline
\end{tabular}
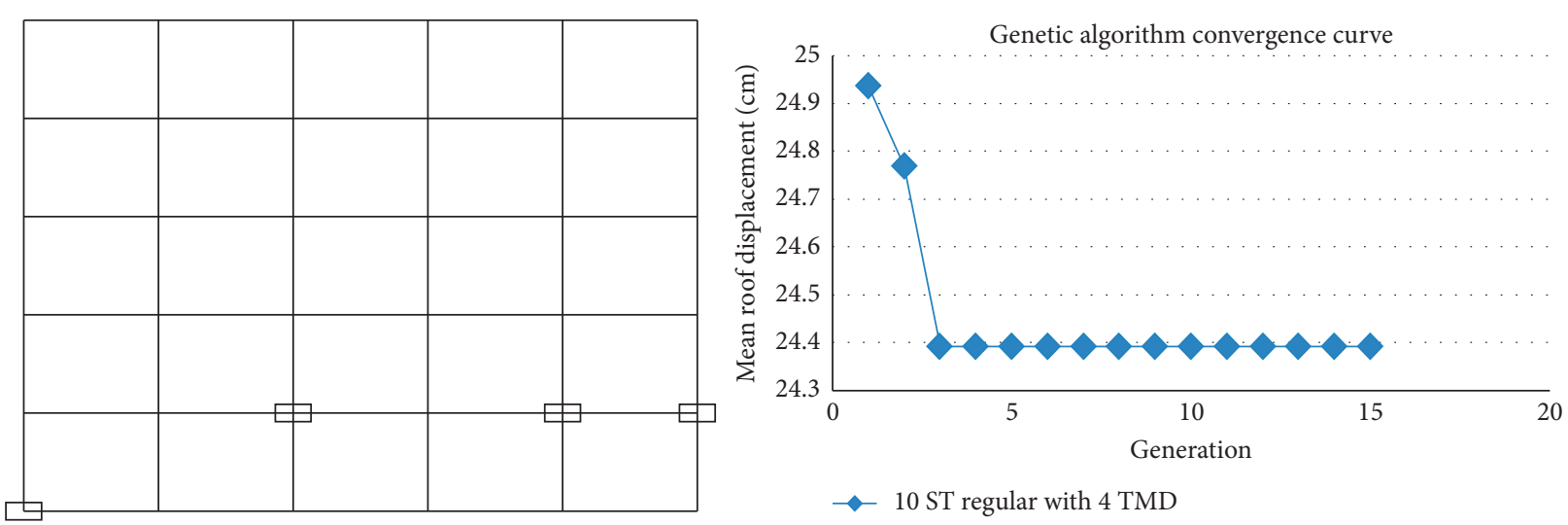

FIGURE 16: Convergence diagram of the ten-story model with 4 dampers in genetic algorithm (right) and damper optimal positions (left).
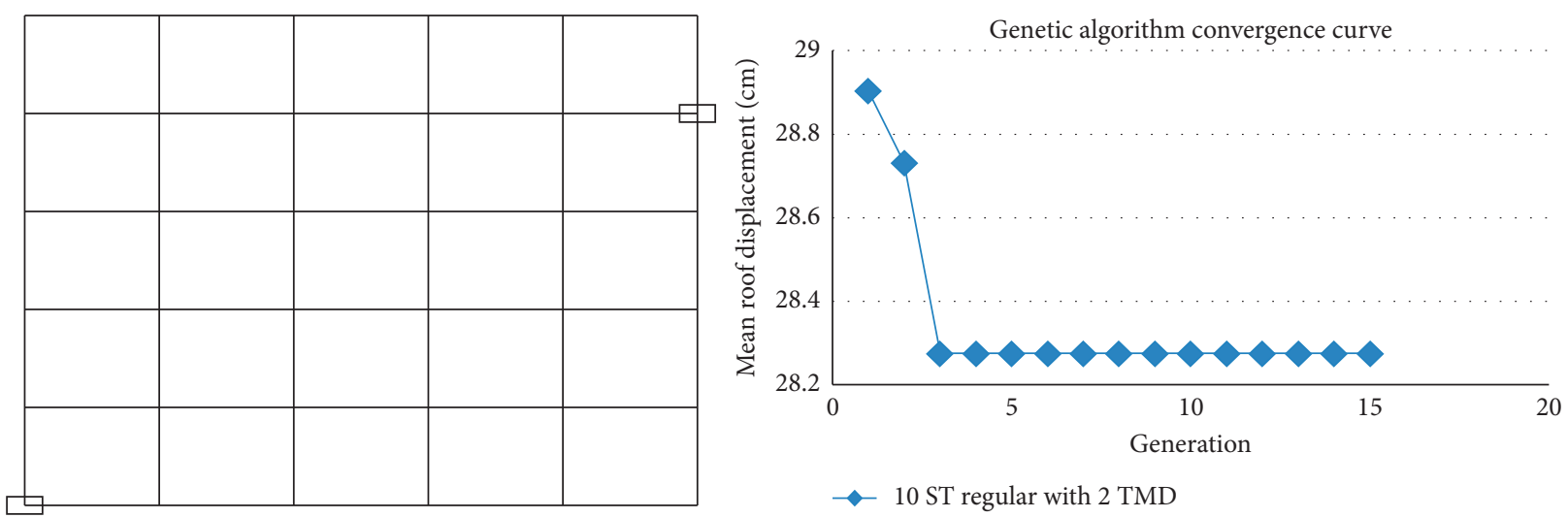

FIGURE 17: Convergence diagram of the ten-story model with 2 dampers in genetic algorithm (right) and damper optimal positions (left). 


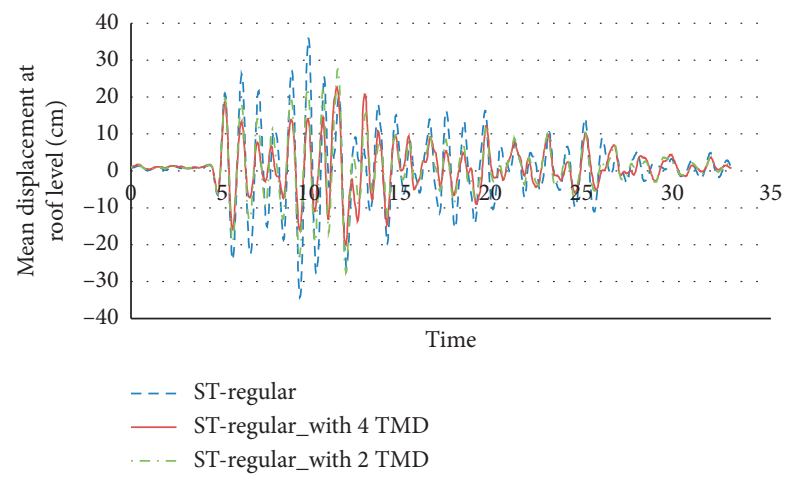

FIGURE 18: Displacement of the ten-story regular model with 2 and 4 dampers.
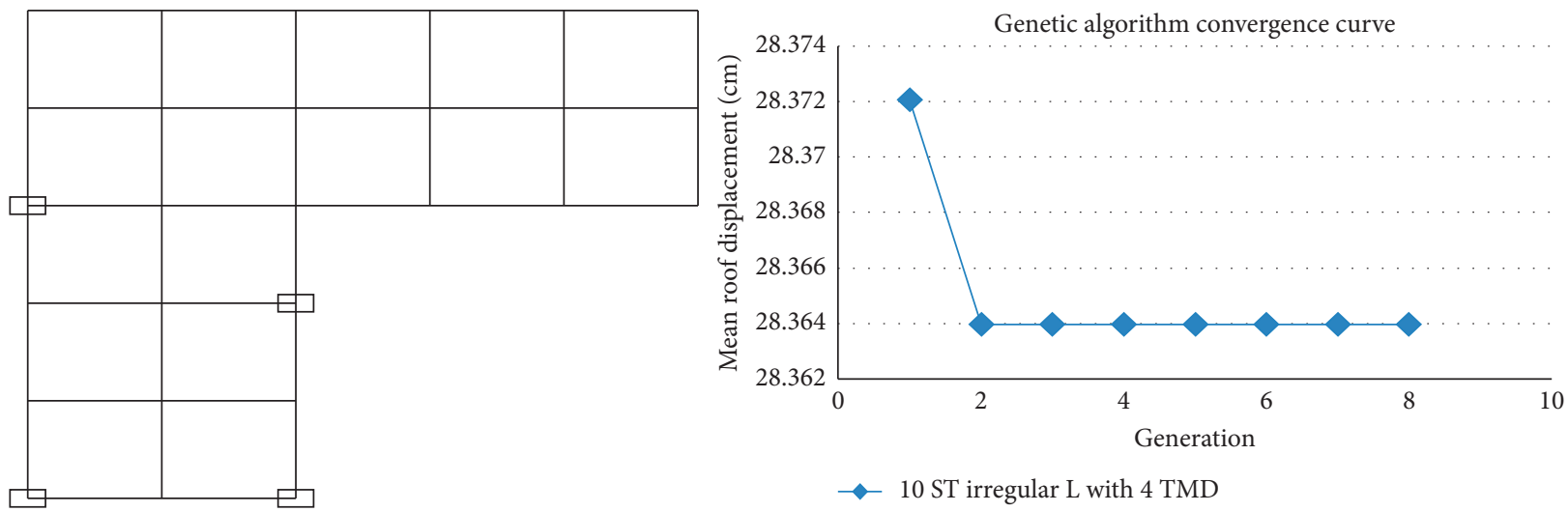

FIGURE 19: Convergence diagram of the ten-story model with 4 dampers in genetic algorithm (right) and damper optimal positions (left).
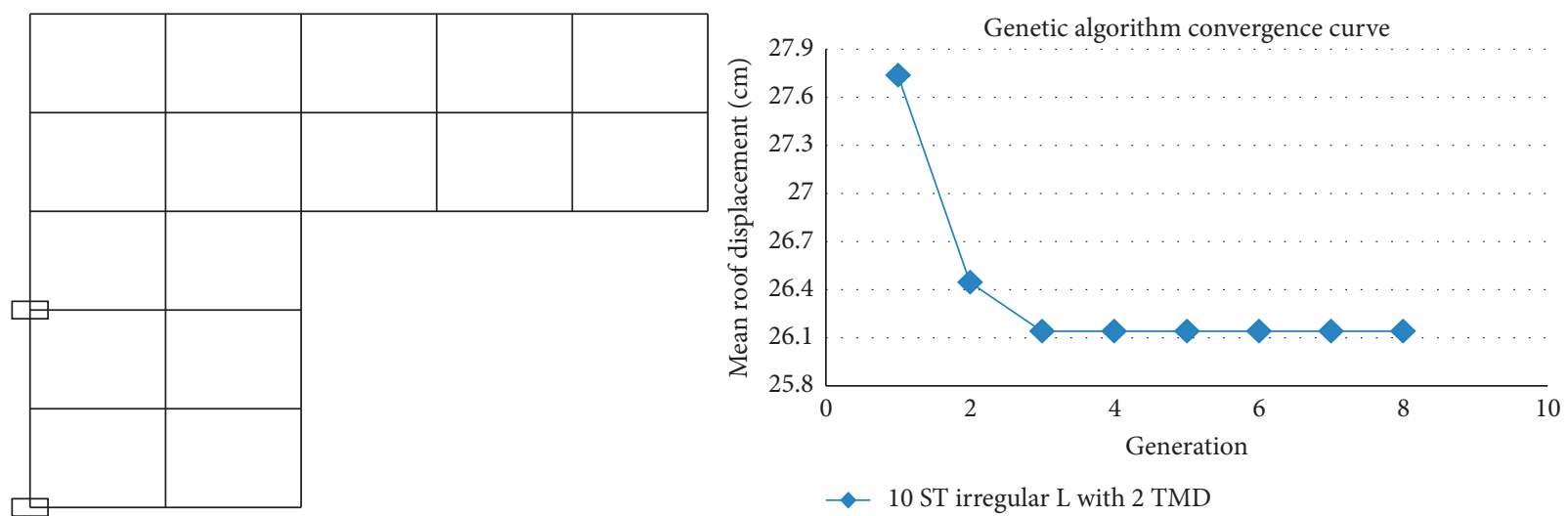

Figure 20: Convergence diagram of the ten-story model with 4 dampers in genetic algorithm (right) and damper optimal position (left).

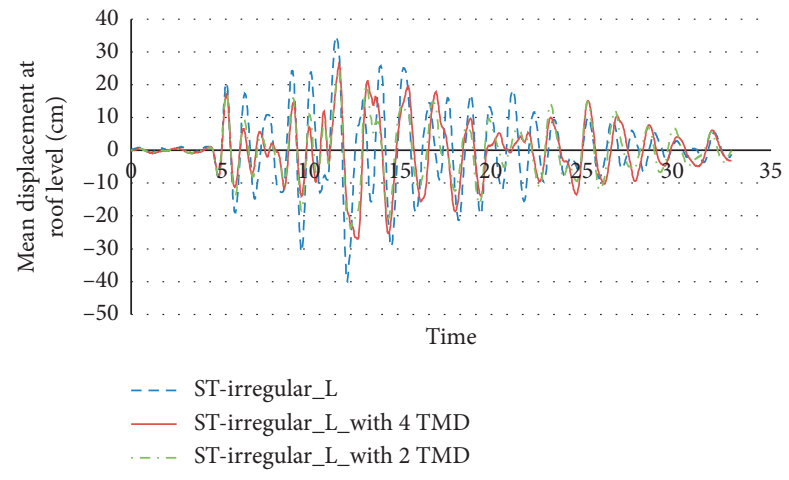

Figure 21: Displacement of the ten-story irregular L-shaped model with 2 and 4 dampers. 

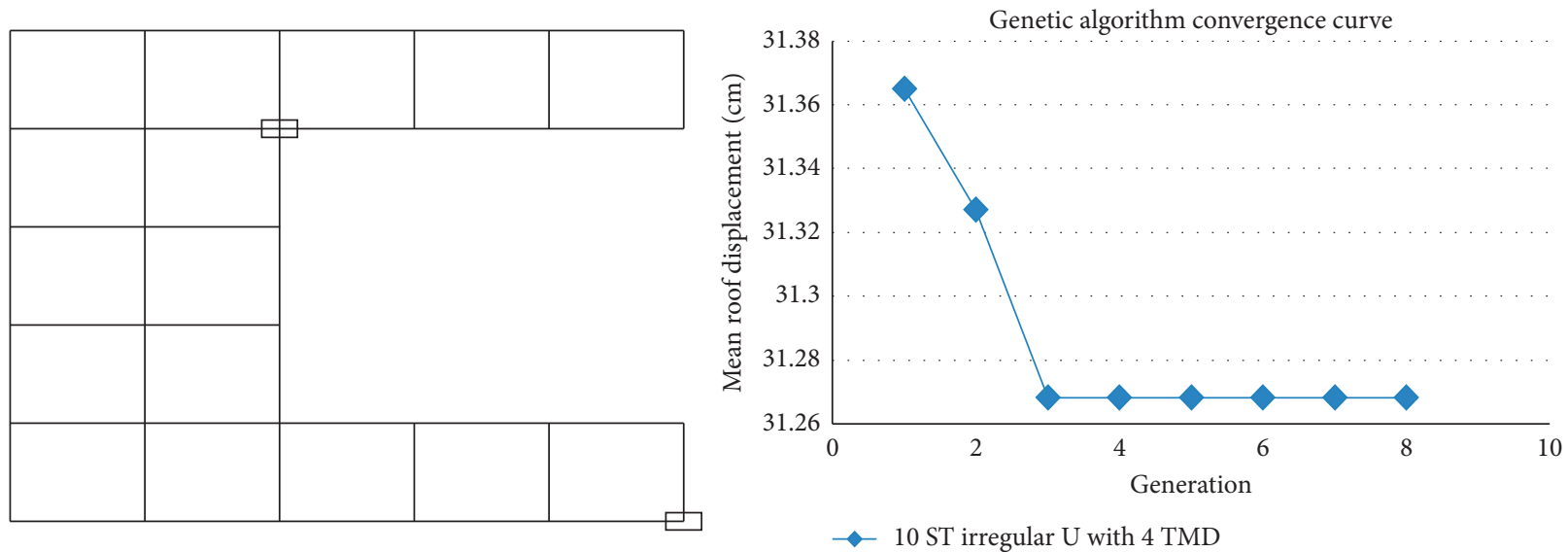

FIgURE 22: Convergence diagram of the ten-story U-shaped model with 4 dampers in genetic algorithm (right) and damper optimal positions (left).
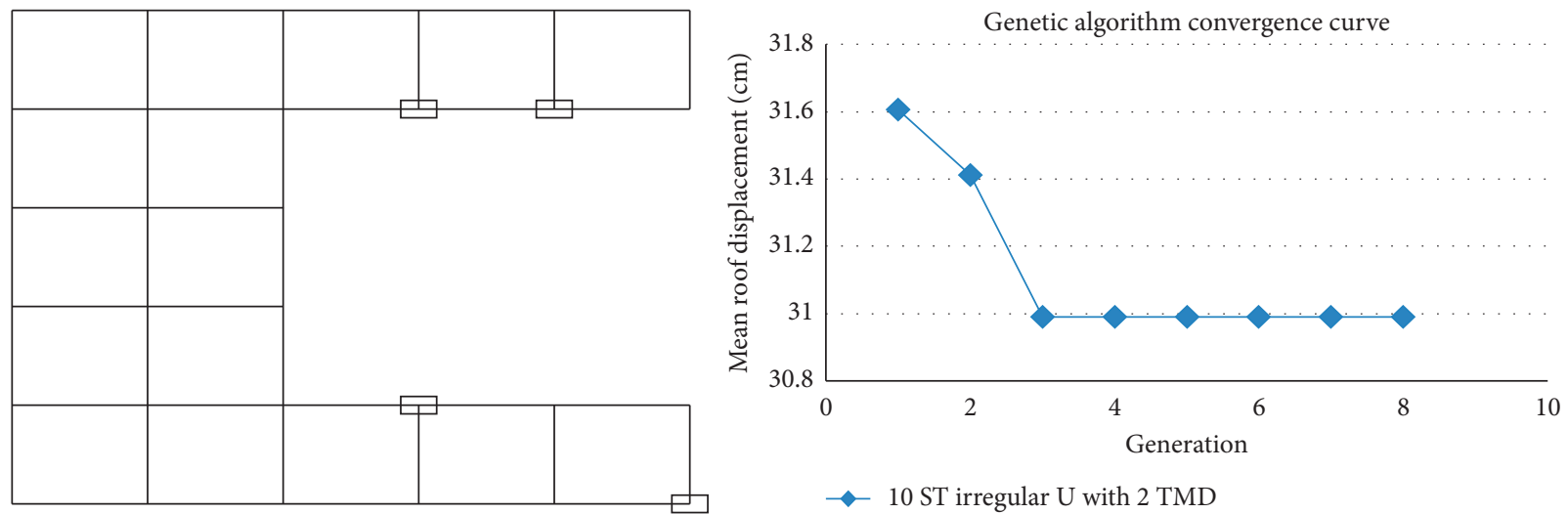

FIgURE 23: Convergence diagram of the ten-story U-shaped model with 2 dampers in genetic algorithm (right) and damper optimal positions (left).

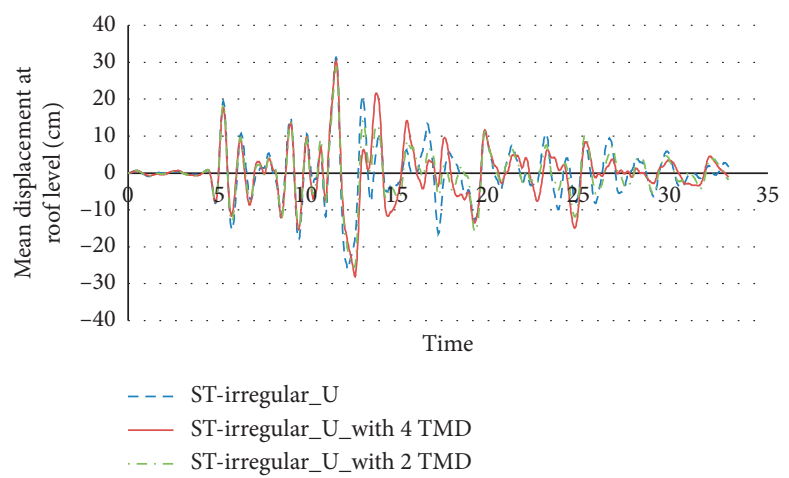

Figure 24: Displacement of the ten-story irregular U-shaped model with 2 and 4 dampers.

condition with four dampers, where these numbers are the number of nodes at the roof level), the structure is programmed and analyzed by MATLAB using API functions and the maximum displacement of the roof is considered as the output of the cost function. All steps of creating, analyzing, and capturing the output are performed automatically using the code written in MATLAB in the cost function section, and finally the optimal position of the dampers for 1 ,
2 , and 4 dampers is reported. The continuous version of genetic algorithm is utilized in this paper (because the continuous version converges earlier and requires fewer generations, coding and decoding steps are not required, and the execution time of the program is also short).

Thus, at the beginning of the algorithm, the number of $N$ positions $(2,1$, or 4$)$ is randomly selected as input variables and in 30 different conditions (population numbers). These 

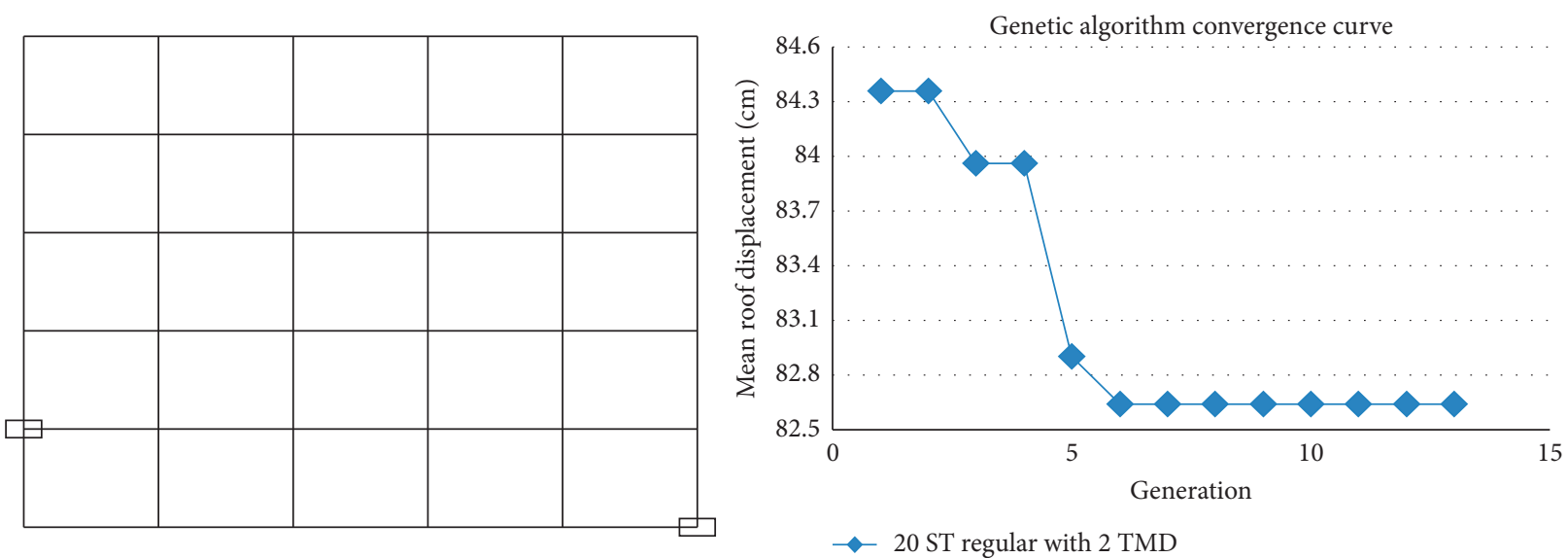

FIGURE 25: Convergence diagram of the twenty-story model with 2 dampers in genetic algorithm (right) and damper optimal positions (left).
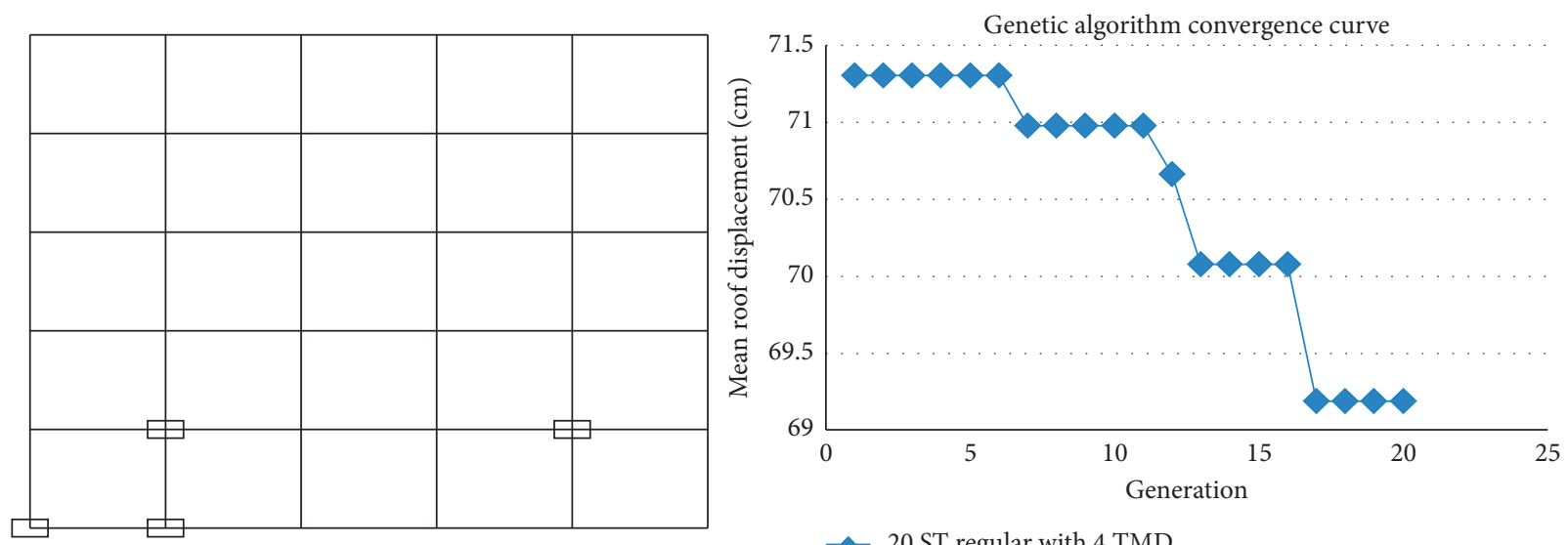

FIGURE 26: Convergence diagram of the twenty-story model with 4 dampers in genetic algorithm (right) and damper optimal positions (left).

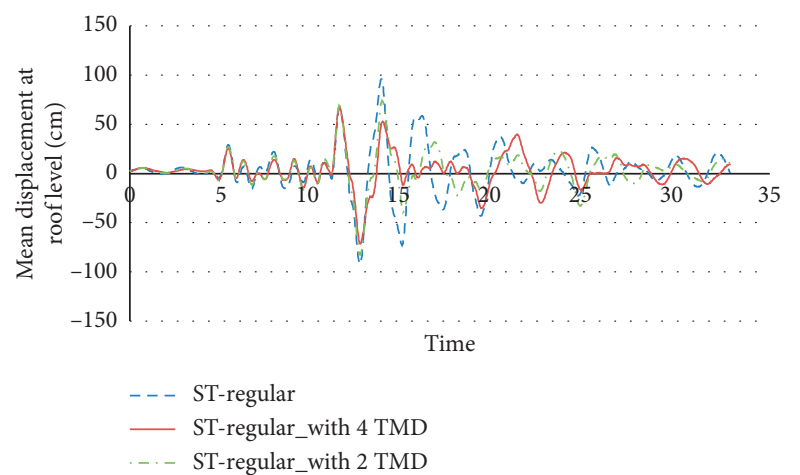

FIGURE 27: Displacement of the twenty-story regular model with 2 and 4 dampers.

variables are the corresponding node number at the roof level of the model created in SAP2000 software, which is defined as a set in MATLAB, and the algorithm uses this set randomly to select variables. For example, to check the optimal position of two dampers in the structure, 30 double families from this collection are selected randomly and entered to the algorithm as the initial population; then, with the initial implementation of the algorithm, 30\% of this population (9 numbers) will be transferred directly to the next generation, and the rest will be included in the transplant and mutation operations and will be the results of the new generation. As mentioned earlier, the cost of each chromosome is calculated in the population generated by the API of the SAP2000 program. In this way, using the API and MATLAB, in each position in each population chromosome, a TMD number with the relevant specifications is placed and the structure is analyzed and the result is extracted as the maximum displacement in the roof level. It should be noted that, in this method, the model without damper in SAP2000 has already been created and the steps of adding damper and analyzing and extracting the results are done by coding. These steps have been repeated for 30 generations. Taking into account the population number and selection rate in each generation of the genetic algorithm, about 700 combinations of different positions of dampers in each model have been investigated. The cost function in the analysis genetic algorithm is considered to be the roof displacement.

In all models, after a maximum of 4 generations, the response to the constant value has been converged, but in order to ensure that the answer to the problem has continued for up to 8 generations, it means for each model about 240 different damper combinations have been examined and 

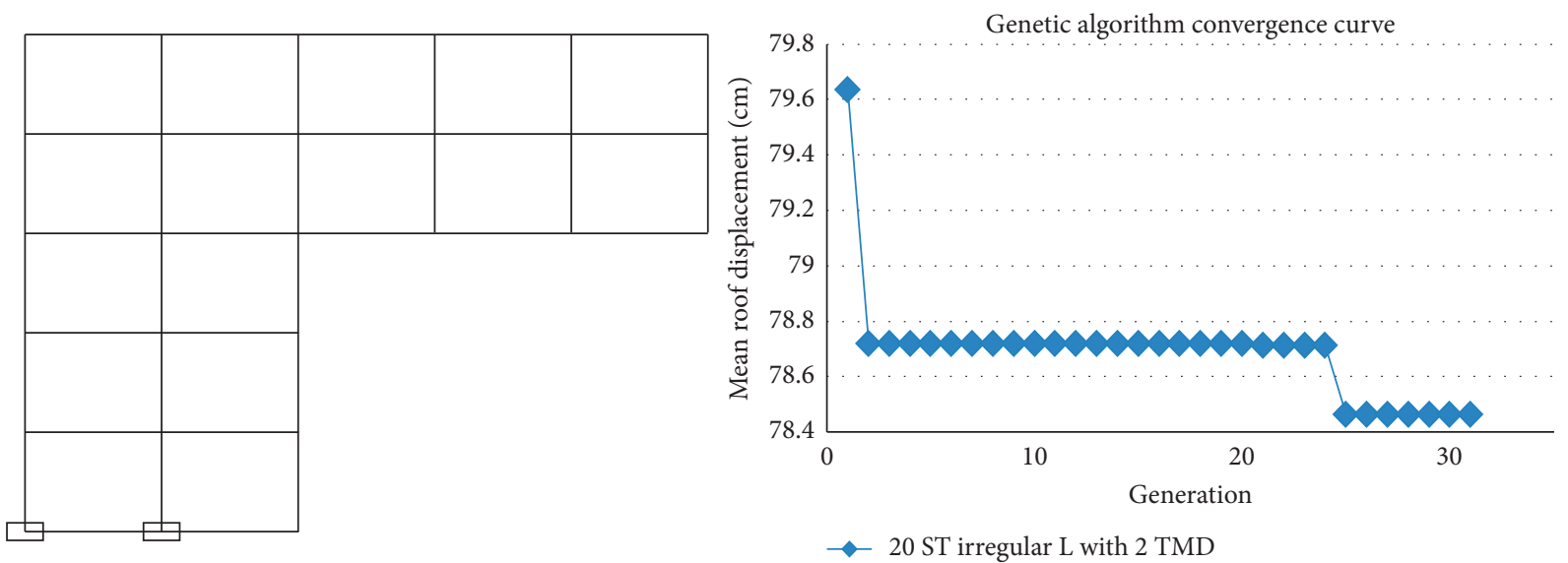

FIgURE 28: Convergence diagram of the twenty-story irregular L-shaped model with 2 dampers in genetic algorithm (right) and damper optimal positions (left).
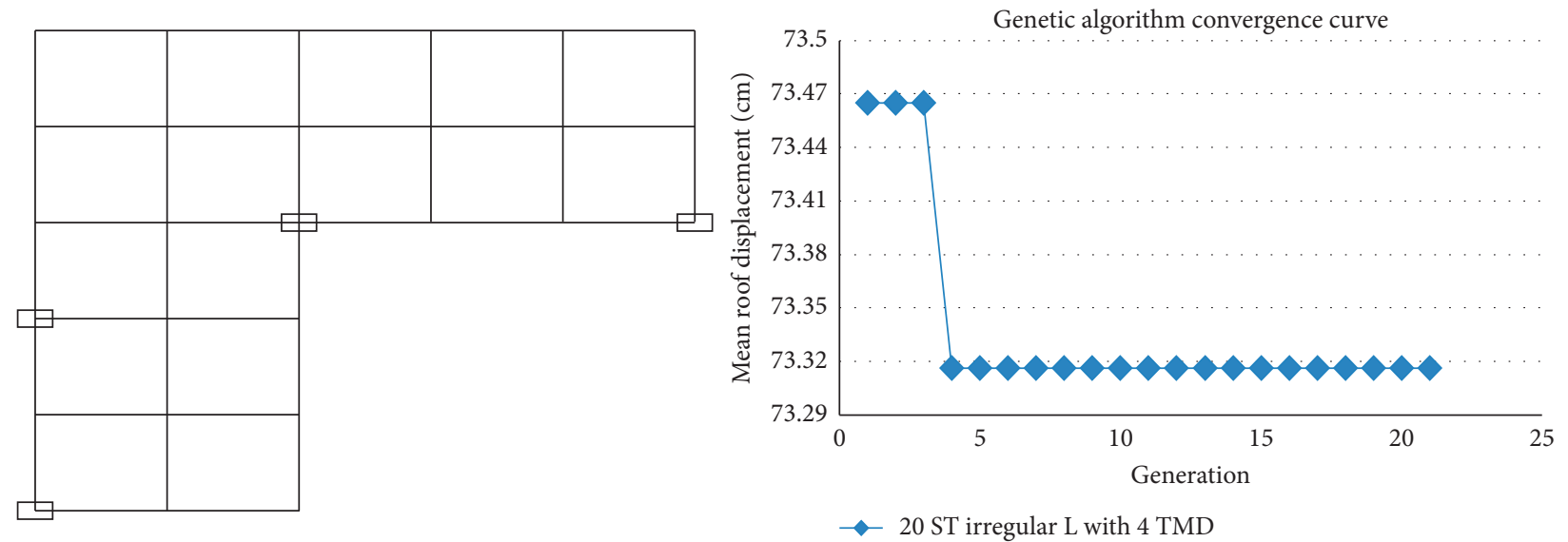

Figure 29: Convergence diagram of the twenty-story irregular L-shaped model with 4 dampers in genetic algorithm (right) and damper optimal positions (left).

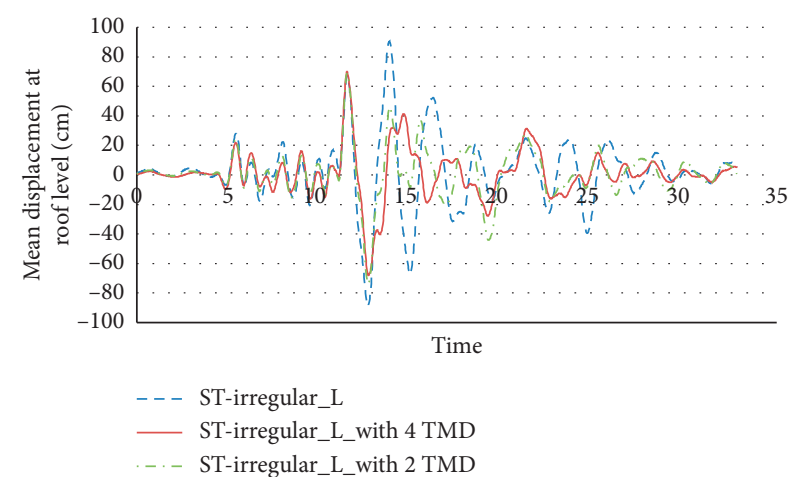

Figure 30: Displacement of the twenty-story irregular L-shaped model with 2 and 4 dampers.

in 8 generations all cases have been checked. The stop limitation was not to change the function of the target and the roof movement.

10.1. Modelling and Analysis of Structures. Nonlinear time history analysis under the El Centro earthquake is used to analyze the structures. The analysis output used to compare and evaluate the number and position of dampers is the maximum displacements of the roof. Modelling, analysis, and comparison of the outputs for different models are performed using the SAP software API.

10.2. API Programming Interface in SAP2000. API programming interface is a valuable tool for CSI software such as SAP and ETABS that allow engineers to exploit them with coding language such as Visual Basic under Excel (VBA), C\#, $\mathrm{C}++$, MATLAB, Fortran, and Python. In other words, an engineer using API is capable of coding all ETABS and SAP software commands and tools and accomplishes tasks such as modelling, loading, analyzing, and extracting a variety of results. Engineers can build custom work tools using the API to control CSI software. These tools are able to repeatedly perform timeconsuming tasks in a matter of seconds without human error.

10.3. Model Description and Optimization Method for Damper Placement. In this section, the effects of 2 and 4 dampers on the roof level for 10- and 20-story structures are investigated. 

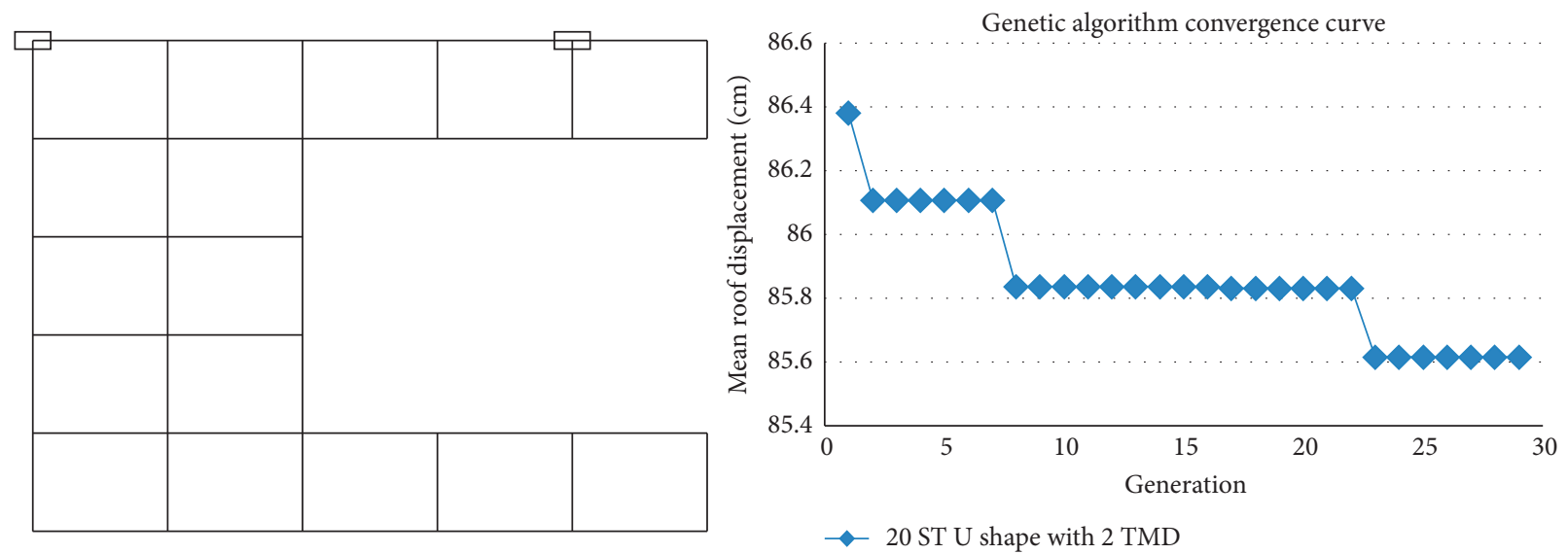

FIGURE 31: Convergence diagram of the twenty-story irregular U-shaped model with 2 dampers in genetic algorithm (right) and damper optimal positions (left).
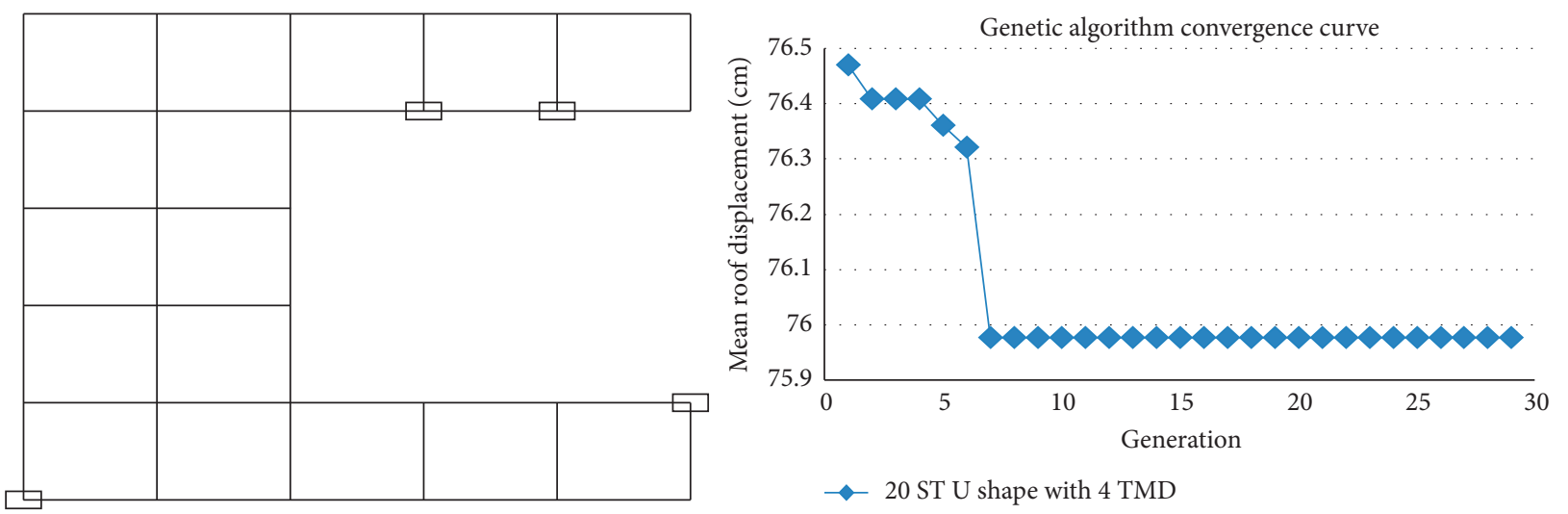

FiguRE 32: Convergence diagram of the twenty-story irregular U-shaped model with 4 dampers in genetic algorithm (right) and damper optimal positions (left).

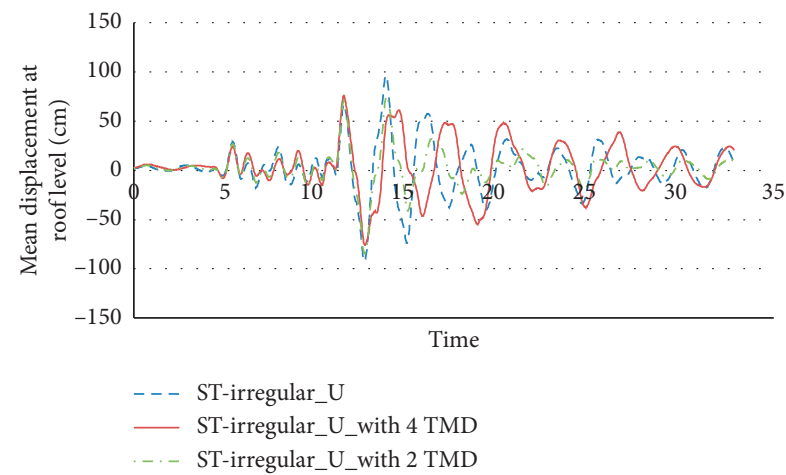

FIGURE 33: Displacement of the twenty-story irregular U-shaped model with 2 and 4 dampers.

For this purpose, the genetic algorithm is used to find the optimal position of these dampers for each number of dampers, so that the position of the structural nodes in the roof level ( $N$ variables equal to the number of dampers) is considered as the variable and the optimal combination of these variables is obtained. The cost function of the algorithm is compiled using the SAP software API, for each chromosome in the population consisting of such variables as $5,9,12$, and 32 for the case of using 4 dampers, where these numbers are the node numbers in roof level. The structure is created and analyzed using API functions and the maximum roof displacement is considered as the cost function output. All the steps of creating, analyzing, and getting output are done using the code written in MATLAB in the Cost Function section. The algorithm parameters are shown in Table 11.

10.4. Results of Optimal Location of Dampers in 10-Story Regular and Irregular Structures. All models converged to a constant value after a maximum of 4 generations, but it continued for up to 8 generations to ensure the problem is answered (approximately 240 different damper combinations are examined for each model). The locations of the dampers in the cases of using 4 and 2 dampers obtained from genetic algorithm are shown for different structures in Figures 16-24.

The results indicate the significant effects of the mass dampers on the structures. Multiple dampers' symmetrical placement in the plan also plays an important role in the results and responses and the changes in the positions of dampers have insignificant effect in the response of the 
structure if their overall positional symmetry does not disagree with the plan axes. In other words, proper and symmetric mass distribution of the mass dampers in the plan plays an important role in reducing the seismic responses of the structures. It can also be noted that the mass dampers with their mass and stiffness change the dynamic characteristics of the structures and affect the seismic responses. Therefore, if the placement of the mass dampers can bring the centre of mass closer to the centre of rigidity, it can reduce the amount of irregularities and its effects and optimize the seismic behavior of the structure. What is considered in determining the optimum position of the mass dampers is their symmetrical positioning which improves the seismic response of the structures. In irregular U-shaped structures, the distribution of dampers is almost symmetric. As it can be seen, the damper optimal positioning approaches the centres of mass and rigidity to each other and reduces the eccentricity and, as a result, improves the responses in irregular L-shaped structures.

10.5. Optimal Position Results of Dampers in Regular and Irregular Twenty-Story Structures. All models converged to a constant value after a maximum of 4 generations, but it continued for up to 8 generations to ensure the problem is answered (approximately 240 different damper combinations are examined for each model). The locations of the dampers in the cases of using 4 and 2 dampers obtained from genetic algorithm are shown for different structures in Figures 25-33.

\section{Conclusions}

In this research, the effects of optimal number and position of multiple mass dampers on 10 and 20 regular and irregular steel buildings are investigated. The increasing use of high-rise buildings for economic and technical reasons has led to increased research into the control of such structures against earthquake and wind forces and their technical efficiency. Plan irregularity is also one of the important issues that designers and earthquake specialists face. In this research, a wide range of near- and far-field records with different earthquake intensities and parameters are used, and the dampers are designed and installed with respect to the dynamical relationships and the models are analyzed by nonlinear time history analysis. The results show a more desirable effect of using more dampers in models than single mass dampers. Placing dampers at more than one point further reduces the seismic response of the structures and increases the reduction rate of each response such as base shear, displacement, and acceleration of floors. As the dampers are positioned at different points, the mass distribution at the floor level is increased; thereby the applied force by the accelerated mass and the responses are reduced, but when the concentrated mass is positioned at one point of the structure, the applied acceleration to the point is increased and thereby less control is achieved over the seismic response of the structure. The results show that, in most far- and near-field records, when the dampers are positioned at four symmetrical points in the plan, the internal effort of the resisting members in a story is simultaneously contributed against the increasing applied forces by mass and thereby the responses of the structure are reduced due to the reduction of applied acceleration to the floors and the increase of the time period by controlling the amount of torsion in the irregular structures and the appropriate mass distribution between the lateral elements. It is observed that the effect of mass dampers for different earthquake records has considerable differences, because the characteristics and frequency content of far- and nearfield records have differences such as maximum ground acceleration (PGA), magnitude, distance from the fault, the amount of energy released, and the durability, so adding a mass damper changes the dynamic properties and affects the effective frequency of the structure. In the same number of dampers in the far-field records, there is a reduction in the acceleration changes and in the near-field records, the maximum acceleration is observed. In general, multiple dampers in the near-field domain have a better performance in reducing the acceleration of the models, which is also true for floor displacements. The story base shear reduction is observed in the near-field domain and increasing number of dampers. The $45 \%$ reduction on average for displacement, base shear, and acceleration of the model floors using multiple mass dampers clearly indicates the appropriate performance of this device in improving the performance of structures. The results show that there is no significant change in the results of the seismic parameters due to changing the dampers position from the tenth floor to the ninth floor. In the ninth floor, the increase in the number of dampers also indicates the distribution of the dampers mass and the contribution of the dampers in controlling the response and the optimal performance of the structure. In irregular L-shaped structures, the position of the dampers in optimal mode brings the mass centre closer to the centre of rigidity and reduces the rate of eccentricity, and the results are significantly improved. Therefore, if the placement of mass dampers can bring the centre of mass closer to the centre of rigidity, it can reduce the irregular value and its effects and optimally improve seismic behavior. What has been considered in determining the optimal position of mass dampers is their symmetrical placement, which has improved seismic response in structures. In irregular U-shaped structures, the distribution of dampers has been almost symmetrical. In the case of optimum positioning using genetic algorithm, the results show that the symmetry of the dampers position in the plan plays an important role in the results and responses, and the positioning of multiple dampers symmetrically in the irregular structures plan plays an important role in the results and responses and the position changes of each damper are neglectable in the seismic response of the structures if their overall position relative to the plan axis is preserved. In other words, the appropriate and symmetric mass distribution of the dampers in the plan has an important role in reducing the seismic response of the structures. In irregular L-shaped structures, the damper optimal position approaches the centre of mass to the 
centre of rigidity, reduces the eccentricity, and improves the results significantly.

\section{Data Availability}

No data were used to support this study.

\section{Conflicts of Interest}

The authors declare that they have no conflicts of interest.

\section{References}

[1] K. Bargi, Fundamentals of Earthquake Engineering, University of Tehran, Tehran, Iran, 1st edition, 2007.

[2] M. Soto, "Investigation of passive control of irregular building structures using bidirectional tuned mass damper," M.Sc. thesis, The Ohio State University, Columbus, OH, USA, 2012.

[3] M. Abbasi, "Investigating and evaluating the performance of mass-dampers regulated in reducing the non-elastic seismic requirements of tall buildings," M.Sc. thesis, University of Rajaee, Tehran, Iran, 2012.

[4] H. Frahm, "Device for damping of bodies," US Patent No 989, 1911.

[5] J. Ormondroyd and J. P. Den Hartog, "The theory of dynamic vibration absorber," Transactions of the ASME, vol. APM50-7, pp. 9-22, 1928.

[6] G. Chen, "Multi-stage tuned mass damper," in Proceedings of the 11th World Conference on Earthquake Engineering, Acapulco, Mexico, 1996.

[7] A. Clark, "Multiple passive tuned mass dampers for reducing earthquake induced building motion," in Proceedings of the 9th World Conference on Earthquake Engineering, vol. 5, pp. 779-784, Kyoto, Japan, 1988.

[8] R. McNamara, “Tuned mass dampers for buildings," Journal of the Structural Division, ASCE, vol. 103, no. 9, pp. 17851798, 1977.

[9] G. B. Warburton and E. O. Ayorinde, "Optimum absorber parameters for simple systems," Earthquake Engineering and Structural Dynamics, vol. 8, no. 3, pp. 197-217, 1982.

[10] R. Villaverde and L. A. Koyama, "Damped resonant appendages to increase inherent damping in buildings," Earthquake Engineering \& Structural Dynamics, vol. 22, no. 6, pp. 491-507, 1993.

[11] P. Wirsching and G. W. Campbell, "Minimal structural response under random excitation using the vibration absorber," Earthquake Engineering and Structural Dynamics, vol. 2, pp. 303-312, 1974.

[12] M. Abé and T. Igusa, "Tuned mass dampers for structures with closely spaced natural frequencies," Earthquake Engineering \& Structural Dynamics, vol. 24, no. 2, pp. 247-261, 1995.

[13] R. S. Jangid, "Dynamic characteristics of structures with multiple tuned mass dampers," Structural Engineering and Mechanics, vol. 3, no. 5, pp. 497-509, 1995.

[14] C. Li, "Performance of multiple tuned mass dampers for attenuating undesirable oscillations of structures under the ground acceleration," Earthquake Engineering \& Structural Dynamics, vol. 29, no. 9, pp. 1405-1421, 2000.

[15] A. Kareem and S. Kline, "Performance of multiple mass dampers under random loading," Journal of Structural Engineering, vol. 121, no. 2, pp. 348-361, 1995.

[16] M. M. Abdullah, J. H. Hanif, A. Richardson, and J. Sobanjo, "Use of a shared tuned mass damper (STMD) to reduce vibration and pounding in adjacent structures," Earthquake Engineering \& Structural Dynamics, vol. 30, no. 8, pp. 11851201, 2001.

[17] S. M. Zahrai and A. Ghannadi, "Seismic performance of TMDs in improving the response of MRF building," Scientia Iranica, vol. 15, no. 1, pp. 21-33, 2008.

[18] A. Tuan and G. Q. Shang, "Vibration control in a 101-storey building using a tuned mass damper," Journal of Applied Science and Engineering, vol. 17, no. 2, pp. 141-156, 2014.

[19] S. Hirde and R. Aher, "Seismic evaluation of irregular structures," International Journal of Engineering Research, vol. 5, pp. 750-755, 2016.

[20] M. G. Soto and H. Adeli, "Optimum tuning parameters of tuned mass dampers for vibration control of irregular highrise building structures," Journal of Civil Engineering and Management, vol. 20, no. 5, pp. 609-620, 2014.

[21] M. R. Wakchaure, A. Shirish, and R. Nikam, "Study of plan irregularity on high-rise structures," International Ournal of Innovative Researche Development, vol. 1, no. 8, pp. 269-281, 2012.

[22] E. Valmundson and J. M. Nau, "Seismic response of building frames with vertical structural irregularities," Journal of Structure Engineering, ASCE, vol. 123, no. 1, pp. 30-41, 1997.

[23] B. S. K. Reddy, L. Madhavi, and C. H. Srikanth, "Analysis of irregular high raised RCC buildings by using tuned mass damping system," International Journal of Advanced Engineering Research and Science (IJAERS), vol. 5, no. 3, 2018.

[24] S. Bagheri and V. Rahmani-Dabbagh, "Seismic response control with inelastic tuned mass dampers," Engineering Structures, vol. 172, pp. 712-722, 2018.

[25] W. Wang, X. Wang, X. Hua, G. Song, Z. Chen, and Z. Chen, "Vibration bridge deck by a single- side pounding tuned mass damper," Journal of Engineering Strucures, vol. 173, pp. 61-75, 2018.

[26] L. Li and C. Peng, "Novel approach of a nonlinear tuned mass damper with duffing stiffness," Journal of Engineering Mechanics, vol. 143, no. 4, Article ID 04017004, 2017.

[27] Z. Lu, L. Kun, and Z. Ying, "Comparative studies on structures with a mass damper and particle damper," Journal of Aerospace Engineering, vol. 31, no. 6, Article ID 04018090, 2018.

[28] J.-L. Lin, "Top-story mass dampers for seismic control of the first triplet of vibration modes of two-way asymmetric-plan buildings," Journal of Vibration and Control, vol. 23, no. 18, pp. 2962-2976, 2017.

[29] Z. Lu, K. Li, and Y. Zhou, "Comparative studies on structures with a tuned mass damper and a particle damper," Journal of Aerospace Engineering (ASCE), vol. 31, no. 6, 2018.

[30] R. Kamgar, M. Khatibinia, and M. Khatibinia, "Optimization criteria for design of tuned mass damper including soilstructure interactive effect," International Journal of Optimization in Civil Engineering, vol. 9, no. 2, pp. 213-232, 2019.

[31] S. Elias and V. Matsagar, "Siesmic vulnerability of a nonlinear building with distributed multiple tuned vibration absorbers," Structure and Infrastructure Engineering, vol. 15, no. 8, pp. 1103-1118, 2019.

[32] H. R. Rahmani and C. Könke, "Seismic control of tall buildings using distributed multiple tuned mass dampers," Advances in Civil Engineering, vol. 2019, Article ID 6480384, 19 pages, 2019.

[33] M. Yucel, G. Bekdaş, S. M. Nigdeli, and S. Sevgen, "Estimation of optimum tuned mass damper parameters via machine learning," Journal of Building Engineering, vol. 26, Article ID 100847, 2019.

[34] B. Keshtegar and S. Etedali, "Nonlinear mathematical modeling and optimum design of tuned mass dampers using 
adaptive dynamic harmony search algorithm," Structural Control and Health Monitoring, vol. 25, no. 7, p. e2163, 2018.

[35] S. M. Nigdeli and G. Bekdaş, "Optimum design of multiple positioned tuned mass dampers for structures constrained with axial force capacity," The Structural Design of Tall and Special Buildings, vol. 28, no. 5, p. e1593, 2019.

[36] M. Shahi, M. R. Sohrabi, and S. Etedali, "Seismic control of high-rise buildings equipped with ATMD including soilstructure interaction effects," Journal of Earthquake and Tsunami, vol. 12, no. 3, Article ID 1850010, 2018.

[37] S. Etedali, M. Akbari, and M. Seifi, "MOCS-based optimum design of TMD and FTMD for tall buildings under near-field earthquakes including SSI effects," Soil Dynamics and Earthquake Engineering, vol. 119, pp. 36-50, 2019.

[38] F. Sadek, B. Mohraz, A. W. Taylor, and R. M. Chung, "A method of estimating the parameters of tuned mass dampers for seismic applications," Earthquake Engineering \& Structural Dynamics, vol. 26, no. 6, pp. 617-635, 1997.

[39] Building and Housing Research Center, Iranian Code of Practice for Seismic Resistant Design of Buildings, Building and Housing Research Center, Tehran, Iran, 2015.

[40] G. Chen and N. Wu, "Experimental study multiple tuned mass dampers to reduce seismic responses of a three-storey building structure," Earthquake Engineering and Structural Dynamics, vol. 32, pp. 793-810, 2003. 